\title{
TOWARD A NON-REDUCTIONIST ACCOUNT OF LAW AND THE LEGAL REGULATION OF ABORTION IN CANADA
}

\section{by}

TREVOR PURVIS B.P.A.

A thesis submitted to the Faculty of Graduate studies and Research in partial fulfilment of the requirements for the degree of

Master of Arts

Department of Sociology

\author{
Carleton University \\ ottawa, ontario \\ August 26, 1991 \\ (c) copyright \\ 1991, Trevor Purvis
}


of Canada

Canadian Theses Service Service des thèses canadiennes
The author has granted an irrevocable nonexclusive licence allowing the National Library of Canada to reproduce, loan, distribute or sell copies of his/her thesis by any means and in any form or format, making this thesis available to interested persons.

The author retains ownership of the copyright in his/her thesis. Neither the thesis nor substantial extracts from it may be printed or otherwise reproduced without his/her permission.
L'auteur a accordé une licence irrévocable et non exclusive permettant à la Bibliothèque nationale du Canada de reproduire, prêter, distribuer ou vendre des copies de sa thèse de quelque manière et sous quelque forme que ce soit pour mettre des exemplaires de cette thèse à la disposition des personnes intéressées.

L'auteur conserve la propriété du droit d'auteur qui protège sa thèse. Ni la thèse ni des extraits substantiels de celle-ci ne doivent être imprimés ou autrement reproduits sans son autorisation. 


\section{Abstract}

This paper investigates the theoretical bases of a growing call for an eschewal of law as a mechanism whereby progressive social change might be realized. The paper critically examines suggestions that modern societies are undergoing processes of juridification and that such tendencies should be resisted because law is necessarily antithetical to the aspirations of progressive social forces. Looking to the example of the regulation of women's fertility in Canada the paper shows that law has long been instrumental in such regulation and, with the advent of the Charter, has provided potential new space for contestation and rearticulation of the politics of abortion in canada. These realizations call for a conception of law that rejects the reduction of law to extra-legal criteria such as gender or class. The paper moves toward such a non-reductionist account of law, stressing both the political implications of the autopoietic closure of law and highlighting law's role as an interpellative discourse crucial to the constitution of the parameters of the universe of political discourse. 


\section{Acknowl edgements}

Many of the ideas developed in this thesis arose out of the preparation of, and critical response I recieved to, an earlier paper, Feminism, Political strategy and social Struggle: Abortion and Law in the Canadian Context (Purvis 1991). For their critical comments on this earlier paper I am indebted to Amy Bartholomew, Johanna Brenner, Jane Jenson, Heather Jon Maroney, Val Peters and Rob Ryan.

In terms of the immediate project I must express my gratitude to a number of people without whose support, patience and friendship this paper would not have been possible. In particular I would like to thank Amy Bartholomew, Alan Hunt, Rianne Mahon, Donald Peters, Nancy Peters, and Rob Ryan.

I owe particularly deep debts to three people. My parents, Frank and Jean Purvis, have been a consistent source of inspiration and criticism of the most constructive kind. Without their support this project would surely have ended long before it began. Finally, I must thank valerie Peters, whose love, patience, criticism, and keen editorial eye have been an invaluable source of inspiration and strength throughout this project. 


\section{Table of Contents}

Abstract . . . . . . . . . . . . . . . . . . (ii)

Acknowledgements . . . . . . . . . . . . . . . . (iii)

Table of Contents . . . . . . . . . . . . . . . (iv)

Introduction . . . . . . . . . . . . . . . . 1

Chapter I

An Historical Overview of the Legal Regulation of

Women's Fertility in Canada. . . . . . . . 10

The Early Years of Legal Prohibition of Abortion. 11

Practical Resistance and the Growing Impetus for

Reform . . . . . . . . . . . . . 20

The Push for Criminal Code Reform . . . . . . . 24

In the Aftermath of Criminal Code Reform . . . . . 27

Morgentaler and Beyond . . . . . . . . . . 35

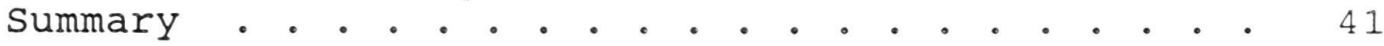

Chapter II

Juridification Tendencies in Advanced Capitalism: The

Legalisation of Politics in Canada . . . . . . . . 43

The Roots of Legalized Politics . . . . . . . . 45

The Legalization of Politics and the Politics of

Abortion . . . . . . . . . . . . 54

The Legalization of Politics: An Assessment . . . 56

Summary . . . . . . . . . . . . . . . 74

Chapter III

The Creeping Hegemony of the Legal order . . . . . . . 76

The Roots of Law's Creeping Hegemony . . . . . . . 78

The Politics of Abortion and the creeping Hegemony of the Legal Order . . . . . . . . . . 82

The Creeping Hegemony of the Legal order: An

Summary Assessment . . . . . . . . . . . 87

Chapter IV

Toward a Non-Reductionist Account of Law . . . . . . 110

Autopoiesis and the Autonomy of Law . . . . . . . 113

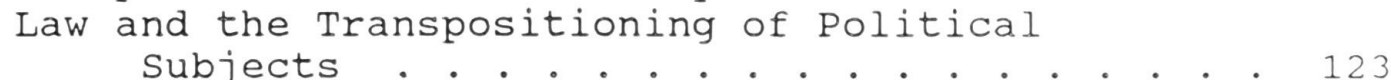

Summary

Subjects • • • • • • • • • • • • • • 123

Conclusions

Law and Struggle: Putting Law Back in

Progressive Politics

Cases Cited

References 


\section{Introduction}

The aim of this paper is to both explore and attempt to provide some insights into an apparent paradox: on the one hand, many within progressive circles today are calling for an eschewal of recourse to law as a mechanism for the achievement of political change. On the other hand, in Canada, a number of recent judicial decisions would, on the surface at least, seem to constitute genuine political victories for progressive forces.

In few places is this paradox more evident than in the case of Canadian feminists' struggles around the issue of the legal regulation of women's fertility. Whilst some (Smart 1989) are calling for a strategic decentring of law in women's politics, women would seem to be making some genuine substantive headway in the legal arena. Of course, many of these authors are writing within the contexts of different national conditions. Nonetheless, there is an effort in many of these works to develop a general approach women should take to law. Arising out of this general theoretical approach to law is a general political prescription - that women avoid recourse to law. This political prescription would, however, seem to warrant further examination in light of the headway canadian women seem to have made in such cases as $\underline{R} \mathrm{~V}$. Morgentaler [1988], 
Tremblay V. Daigle [1989], and R V. Sullivan and Lemay $[1990] \cdot 1$

of course, scepticism about law's utility as a mechanism for the advancement of progressive political aims is hardly recent and is certainly not restricted to feminist authors. Quite the contrary. Socialists have long noted the close connections between the judiciary and dominant social interests and the willingness of the former to bow to the interests of the latter (Marx 1976: 409, 903). Such connections have long served as a pivotal point of reference for instrumentalist analyses. But 'instrumentalist' analyses ultimately beg the question 'Can seemingly genuine instances of progressive victory at law really be marginalized as exceptions?'.

There is a much more sophisticated and nuanced view of the role of law in modern society which arises out of the work of Marx. The focus here is on the tendency for law to isolate individuals by constituting them as free and equal agents before the law, abstracted from their real lived relations of domination/subordination. But insofar as these 'isolation effects' arise primarily out of economic relations, they do not, of themselves, provide an adequate basis for a theoretical understanding of the multifarious complexity of law in the modern world.

${ }^{1}$ Complete references to all cases cited can be found at the end of this paper. 
These approaches have, however, gained both new currency and a new sense of urgency in recent years where analyses of the role of law in advanced societies is concerned. The recent spate of attacks on the judiciary and all things legal has been fuelled by a growing perception amongst many that law is growing; that it is expanding; that it is inserting itself into the most intimate spaces of our lives, seeking to regulate, observe, and discipline our every action. Some seem particularly worried that this tendency toward the juridification of the social is itself inherently bad - that it adds legitimacy to relations of social oppression that we should be attempting to hold up to the light (Glasbeek \& Mandel 1989). Others seem more concerned with the fact that law's growth is connected with a broader drift into an ominous orwellian sort of future in which there is little chance of escaping the gaze of LAW (Smart 1989). Yet others seem far more concerned with the appropriateness of using law as a mechanism for the stimulation of substantive social change (Luhmann 1985; Teubner 1984; Habermas 1987).

This paper is concerned to address some of the multiple facets of this apparent paradox. Ultimately, it attempts to provide a theoretical basis for responding to the question: ' Should progressives use law and legal mechanisms as tools in struggle?'. The response, to be frank, is: 'It depends.' The theory underlying this response suggests that the 
radical potentialities inherent in law are bound by space and time. It is quite simply an historical truth that progressives have often failed to achieve success when law was one (or the) mechanism deployed in an effort to achieve political goals. But, this paper argues, there is little theoretical reason to reject law and legal strategies in general. Indeed, looking at the specific circumstances in which Canadian women find themselves today, recourse to law and legal strategies might not only be prudent, but necessary

The first chapter provides a brief historical overview of the evolution of the abortion issue in canada. Of course the selection of this issue as an empirical referent was not at all innocent. As I noted above, the supreme court of Canada's decision in $\underline{\mathrm{R}} \mathrm{V}$. Morgentaler [1988] stands as a prime example of the paradoxical call for women to eschew law at a time when they might finally be making some headway in the courts.

The selection of the abortion issue arose out of a deliberate attempt to move away from the standard marxist foci on matters more obviously related to the economic 'in the last instance'. Instead, chapter one endeavours to highlight the multiplicity of identities which have come into conflict over the years in the debates surrounding the regulation of women's fertility. Thus, the focus is on professional organization, the law's exclusion of women as a 
legitimate identity in the debate, and women's everyday struggles against the construction of their lived experience as advanced in the discourses of law and medicine. Whilst these experiences are inevitably articulated with the economic, the former cannot be reduced to the latter. Perhaps most conveniently for my purposes, consideration of the abortion issue and the way it has developed in Canadian law permits me an opportunity to critically examine, on their own terms, the merits of two of the theoretical models I present below: each, that is, examines the issue of abortion in their development of a general theoretical position regarding the strategic propriety of progressives pursuing legal strategies as means to effect desired social changes.

chapter two turns its attention to just such a critical assessment. Here I examine Glasbeek and Mandel's (1984) argument that the advent of the canadian charter of Rights and Freedoms in 1982 signals a shift toward the legalization of politics in Canada. They see the advent of the charter as merely one manifestation of a broader trend in advanced capitalist countries toward more law, particularly formal rights guarantees. They argue that states in such countries must take refuge in the mystificatory power of formal legal rights which are necessarily substantively empty.

The chapter opens with a general overview of their theoretical framework, followed by a discussion of how they 
present the abortion issue as one crucial example of their thesis. Using the historical material reviewed in chapter one as a point of reference, this chapter ultimately suggests that Glasbeek and Mandel's approach to law and formal rights is economistic and essentialist. The key redeeming aspect of their work is their focus on the fact that progressives often do fail to achieve their desired political goals when law is the mechanism they choose to do political battle. Importantly, however, there seems to be little evidence to suggest that the legal regulation of women's fertility is part of a broader trend toward juridification.

Chapter three turns to a consideration of a recent feminist intervention into these issues. Carol smart suggests that women beware of 'the siren call of law'(1989: 160) and to resist 'the creeping hegemony of the legal order' (ibid.: 5) whenever and wherever possible. For Smart, law is on the rise. Moreover, it is a key mechanism of discipline in a broader shift towards disciplinarity in the societies of western modernity. Because law is growing, because it is inherently antithetical to the interests of feminism, and because any turn to law thus further legitimates law, smart counsels feminists to decentre law and to struggle for their political objectives on other terrain. 
This chapter offers a critical assessment of smart's position both on law generally, and on her treatment of the abortion issue specifically. The chapter concludes that Smart's theoretical position leaves little room for understanding progressive victories at law as anything other than sham. Ultimately, the chapter concludes that these theoretical weaknesses call for a reassessment of smart's political prescription that law be avoided as a mechanism for advancing social change.

Chapter four develops an alternative theoretical approach to law which endeavours to circumvent some of the problems plaguing the approaches reviewed in chapters two and three. Here the discussion opens with a critical examination of autopoietic theories of law (Luhmann 1985, 1987; Teubner 1984, 1987; Jessop 1987, 1990). The conceptualization of $l a w$ as an autopoietic social sub-system offers a new and potentially more fruitful way of understanding the expansion of the legal order, one that helps avoid some of pitfalls of the approaches examined in chapters two and three. Moreover, this approach offers a new way of theorizing not only the role and nature of law, but the relation of the legal sub-system to its environment and its relationship with other social subsystems. But most contributions to autopoietic analyses present significant lacunae. The most notable of these is a hard-core 
structuralism that leaves little, if any, room for conceptions of agency, strategy or struggle.

Ultimately, chapter four endeavours to re-insert agency and strategy into a conception of the expansion of law in an effort to understand why a potentially expanding, functionally complex legal order might not necessarily bear negative implications for progressive social forces eager to apply law as a tool in struggle. While autopoieticists stress the structural coupling between social sub-systems they tend to take for granted the way that specific configurations of social forces combine in any one conjuncture, in turn placing limits on the range of issues and agents deemed to have a legitimate - i.e. state enunciated and enforced ${ }^{2}$ - position in the contestation of social relations. The paper attempts to provide this conceptual space through a discussion of law's role as an interpellative structure, crucial to the transpositioning of subjectivities and their inclusion/ exclusion from the universe of political discourse (Jenson 1987, 1990; Woodiwiss 1985, 1990).

Using this proposed 'alternative', the concluding chapter engages in a reconsideration of the agents, issues

${ }^{2}$ The focus here is on developments in democratic capitalist societies, and it is these terms that the notion of 'state enunciated and enforced' is taken as conferring some degree of popular legitimacy on some actors' engagements in struggle, whilst providing a basis for the occlusion of others'. 
and events which have surrounded the abortion issue in Canada over the years. Conceiving of law in terms of this alternative - as an autopoietic system which positions social subjects relative to one another and is a crucial determinant of what identities will gain legitimate political voice - permits a more nuanced theoretical account of the evolution of the abortion issue than the approaches of either Glasbeek and Mandel or Smart might cede. The exclusion of women from debates around reproductive issues is, rather, seen to have arisen out a strategic coupling between the legal and medical systems. That coupling is described as one which is increasingly riddled by contradiction arising largely out of women's resistance to law's construction of their lived experiences. Nonetheless, the formal basis of the structural coupling between the two systems was strong enough that it ultimately took a challenge from within the medical community to challenge women's formal exclusion from the universe of political discourse. 


\section{Chapter I}

\section{An Historical overview of the Legal Regulation of women's Fertility in Canada}

The history of the evolution of the abortion debate in Canada is long and complex, and has been dealt with at length by others (Backhouse 1983; Collins 1985; Gavigan 1986; McLaren \& McLaren 1986; Jenson 1990). Whilst it is not my intention to duplicate these efforts, the theoretical discussions which follow this chapter do require some accounting of that complex evolution, its events, and key actors. A review of the many events and identities which have entered the fray in the struggles around the abortion issue helps to highlight the complex nature of social struggle generally. Moreover, a more adequate appreciation of such complexity serves to highlight the inadequacies of some influential recent theoretical interventions which question how we conceive of law and the ways in which law may or may not be used as a mechanism to effect progressive social change. With this in mind, some elaboration of the history of the abortion issue is in order. This chapter attempts to make sense of the events and forces which have shaped the debate over the years.

In Canada, the relationship of women to their reproductive capacities has long been regulated by law for the most part, the criminal law - and a statesanctioned organized professional medical community. In turn, women who have endeavoured to assert control over 
their fertility, and those who would assist them, have often been the objects of criminal sanction. In general terms, the law deemed that issues surrounding abortion were appropriately dealt with by doctors. Whilst women had long intervened in the management of their reproductive careers and had developed a base of practical knowledge regarding their fertility and its management, that knowledge was marginalized by the scientism of medical discourses and its enshrinement in law. Thus, until recently issues of women's reproductivity have gained their chief expression in discourses of criminality and medicalization.

\section{The Early Years of Legal Prohibition of Abortion}

These discourses which had for so long formally excluded women from decisions as to whether or not to get an abortion had their roots in pre-confederation law. It is unclear what the precise motivating factor behind this early legislation was, but there is little indication that there had been any general public outcry surrounding the issue of abortion at that time (Backhouse 1983: 65-66). But, interestingly, the earliest legislated prohibitions on abortion targeted not the women who sought abortions or self-induced miscarriage, but rather abortionists themselves, and those, other than the woman aborting, who would aid in such procedures. This fact suggests that it might be prudent to look to the political dynamics 
surrounding the rise of the legislation - i.e. the actors who engaged in the debate, and the nature of their contributions to that debate. It is in these terms that the statutory regulation of abortion has been closely linked to the efforts of a budding professional medical community (Backhouse 1983: passim; Gavigan 1986: passim).1

The first official legal prohibition of abortion came in England in 1803, a move that was soon to be followed up in British North America and in the US. ${ }^{2}$ The earliest examples of legislated prohibitions on abortion maintained the 'popular' notion of a quickening distinction. That is, the severity of penalties for those who provided women with abortions was determined by whether or not the woman had yet quickened (i.e. experienced foetal movement). By the middle of the century, however, the legislature of Upper Canada had led the way in the abolition of the quickening distinction, a move that would soon be duplicated in the other colonial

${ }^{1}$ In the US and Britain there was a similarly close relationship between the emergence of the medical 'profession' and the rise of legal prohibition of abortion (Petchesky 1990: 67-100; Luker 1984: 11-39; Rothman 1989: 106-124).

'Otherwise known as 'Lord Ellenborough's Act', this first statute was formally known as: An act for the further prevention of malicious shooting, and attempting to discharge loaded fire-arms,... and the malicious using of means to procure the miscarriage of women, 1803 (Eng.), 43 Geo. III, c. 53, ss. 1,2 (as cited in Backhouse 1983: 66). In 1810 New Brunswick passed legislation that would duplicate the new British law (ibid., 67). 
legislatures. ${ }^{3}$ In many ways this move reflected new claims from the medical 'profession' that life begins at conception.

By the end of the nineteenth century, prohibitions on abortion had been enshrined in the newly consolidated Criminal code of Canada [1892]. Moreover, the scope of prohibition had been extended to include pregnant women who would attempt to control their own fertility through selfinducing miscarriage, or those who sought and underwent abortions at the hands of others. Such women were now relegated to the status of 'criminal' and subject to similar criminal sanction (if they survived the procedure) to that risked by either the back-street or professional abortionist. ${ }^{4}$ By the end of the century, abortion had largely disappeared as a primarily moral issue in the traditional sense, and had reemerged as a technical-moral

\footnotetext{
${ }^{3}$ This came with the passage of Upper Canada's offenses Against the Person Act in 1841 .

${ }^{4}$ There is a worthwhile distinction to be made between 'back-street' and 'professional' abortionists. Not all abortions obtained outside of the 'medical' community were terribly unsafe. Criminalization may, however, have given rise to a number of underground, or back-street' sources from whom cheap but unsanitary and unreliable services could be had. There were many 'professional' abortionists who had had the knowledge, experience, and appropriate hygienic facilities to perform the procedure in a relatively safe fashion. Criminalization, however, tended to drive many out of providing the service, whilst prices for obtaining relatively safe abortions were thrown beyond the reach of even more women as the legal ramifications of providing such services became more severe.
} 
issue managed by physicians; ${ }^{5}$ abortion had become 'medicalized'.

In the early years of its efforts to organize, the 'regular' medical profession in Canada waged a relentless 'ideological and legal campaign against abortion [which] helped the profession to establish its monopolistic control over health care.' (Petchesky 1990: 81; cf. Backhouse 1983). In its efforts to consolidate its ranks and promulgate popular (i.e. white, middle class) rejection of 'irregulars' such as 'quacks', folk doctors, and other supposed 'incompetents' (including, for instance, midwives), the regulars lobbied hard for restrictive abortion legislation. Such legislation was crucial to the consolidation of their

${ }^{5}$ Luker's suggestion that abortion had virtually disappeared as a moral issue (1984: 9) is only partially correct. It might, rather, be more appropriate to suggest that doctors called upon their technical expertise as a basis to establish their dominance over moral management. Thus, such issues as the sanctity of life (and its point of commencement), sexual morality, and the biological 'duties' and appropriate place of women of 'good stock', all formed key components of the medical regulars' campaign to dominate the management of issues surrounding reproduction. Through their claim to a monopoly over issues of life and health they could, in turn, claim a monopoly over all 'medical' issues and procedures, including abortion and such morally charged issues as when life begins. Gordon notes that doctors felt a growing 'sense of responsibility and privilege as the guardians of sexual morality. ... [They wanted to be] the arbiters of situations in which exceptions might need to be made' (cited in Backhouse 1983: 124). 
control over medical practice (Backhouse 1983: passim; cf. Luker 1984: passim; Gavigan 1986: 288).6

The new discourse of medicalization surrounding abortion gained further ideological purchase from the rising eugenics movement (Petchesky 1990: 78-96; Backhouse 1983: 73 ff.). In the Canadian case, as in those of the Us and Britain, the newly organized medical community played a central role in promulgating a discourse of 'race suicide'. In the major medical journals of the day, Canadian doctors presented the abortion decision as one that only they were qualified to make - a position inscribed and largely (if ambiguously) protected in the law. Those WASP ${ }^{7}$ women who continued to get abortions were denounced by the medical community - i.e. the organized regulars — as selfish, and shirking their naturally given biological functions (Backhouse 1983: 81). This discourse threatened that the prolific breeding practices of inferior - immigrant and

${ }^{6}$ Backhouse chronicles the steady barrage of antiabortion campaigning that attended the pages of Canadian medical journals through the nineteenth century, particularly in the pages of the canada Lancet (Backhouse 1983: passim).

${ }^{7}$ It should be stressed here that it was WASP women who were generally the primary targets of this rhetoric. In both the popular medical journals of the day, as well as in other of the print media, the focus of attacks on the propriety of abortion and / or contraception were primarily WASP women. The authors of the day were railing against what they saw as dangerous fertility of Roman catholics. The key targets here were Irish immigrants and Quebecois, the revanche des berceaux of the latter being perceived as a particularly poignant threat to English Canada (McLaren \& McLaren 1986: 17). 
native groups, French Canadian Catholics, and the working class - segments of the population would surely lead to social and moral decline (McLaren \& McLaren 1986: 17).

By the end of the nineteenth century the now powerful medical lobby had wrested complete formal/legal control over issues related to abortion from women, a control that went, for the most part, uncontested by women. ${ }^{8}$ The political aspirations of first-wave feminists were concentrated primarily on issues of female suffrage, legal claim to the shared assets of marriage, maternal rights, and formal social recognition of the value of the work women did in society - i.e. in the family and at home (Smart 1989: 141). Popular agitation for political reform of restrictive abortion legislation, while not non-existent, was a political demand generally eschewed by feminists. Much of the early women's movement regarded abortion as antithetical to the interests of women. For the most part, these women were fighting against male promiscuity, and for the sanctity of the family and recognition of the critical place women

${ }^{8}$ Involuntary motherhood was further forced on women by the criminal prohibition 'against the sale, distribution and advertisement of contraceptives, labelling this along with abortifacients as obscene material' (Backhouse 1983: 117). such activities were proclaimed by the hegemonic voices in the regular medical community to 'pervert the highest function of women's nature, and to turn blessings into cursings' (quote from Canada Lancet (1871); cited in ibid., 81). Any last vestiges of formal control that a woman might claim at law over her own reproductive capacities were snuffed out when, in The Queen V. Clarence ( 1889$] 2$ Q. B. 23) married women were denied the right to refuse to engage in coitus with their husbands. 
held therein. In these terms, abortion and contraception were generally to be opposed (Ginsberg 1989: 28-30).9

When the push for birth control reform commenced, it did so largely at the expense of the movement for abortion reform: birth control was pushed into the hands of doctors who were rendered the new legal and legitimate guardians of birth control information and substance dissemination. Abortion reform became arguably less necessary in the face of reformed attitudes about contraception. Thus, whilst militant feminism was not completely absent from the debates over 'reproductive' issues, the orientation of its campaign - reform of contraception legislation - largely undermined any basis for relaxation of existing legal restrictions on abortion, couching abortion largely in terms of an

${ }^{9}$ There were, to be sure, important exceptions to the foregoing. In the United states and Britain there emerged such crucial radical feminist figures as Margaret Sanger and Marie stopes, both very vocal publicists of the merits of and need for women to be able to control their fertility. often, however, interventions such as theirs were aimed only at reform of birth control legislation, relegating abortion to the status of an unfortunate bi-product of inadequate contraception (Petchesky 1990: 54, 89-95).

Another movement aimed at achieving greater control for women over their reproductive capacities began to gain some popular ground during this period. This was the 'voluntary motherhood' campaign. However, much of this campaign was aimed at promoting a woman's right to deny her partner coitus and stressing the need for contraception. It would seem that reform of abortion legislation was not one of the objectives of this movement, perhaps because the movement 'was associated with a push toward a more restrictive sexual morality' (Gordon cited in Backhouse 1983: 127). 
unnecessary and unfortunate corollary of poor dissemination of contraceptive knowledge, technology and practices. ${ }^{10}$

In Canada there were some socialists and socialist feminists in these early years who were committed to expanded availability of contraception and abortion for Canadian women (McLaren \& McLaren: passim). But whilst these movements did lay the bases for future demands for political and social reform, they were riddled by internal conflict over specific reform proposals and a first-order commitment to the working class (McLaren \& McLaren 1986: 141).11 Furthermore, pressure for abortion reform in the Canadian context was closely associated with radical 'Left' politics, an association that may well have undermined its capacity for insertion into popular (particularly central Canadian liberal) discourse.

${ }^{10}$ I use the term 'militant' rather than 'radical' here in describing the activities of feminist activists like Marie stopes and Margaret sanger. Clearly, in their time these women held relatively radical views on issues of sexuality and reproduction. However, I think it is important to distinguish their positions from those of the radical feminism of today. Thus, unlike many others (i.e. McLaren \& McLaren) I prefer to use the term 'militant', as opposed to 'radical', to describe the activities of these early reformers. My choice is not, however, intended to impute any particular insurrectionary proclivities to the politics of these women.

${ }^{11}$ Socialists were divided over whether or not to support reform of abortion and contraception legislation, with some taking the feminist position that it was important that women achieve control over their reproductive capacities, whilst others argued that family size was an economic issue that would take care of itself as economic emancipation was achieved (McLaren \& McLaren 1986: 139-142). 
Thus, the drive by the medical community to consolidate its monopoly over health care issues went largely unopposed. No other collectivity had the organizational capacities, the scientific credentials, or the moral predisposition to effectively lobby the state in an effort to block the growing power of this new professional elite. Certainly the disparate individual abortionists, folk doctors, midwives, etc., could not muster a viable organized opposition. Nor was there a coherent viable counter-position being articulated by feminists or socialists. Professional organization, coherence, and a claim to a natural scientific-technical monopoly over reproductive knowledge enabled medical 'regulars' to propagate a discourse of medicalization around reproductive issues. The object of such organization was legal reform which would grant explicit and exclusive recognition to a medical monopoly over both health issues in general, and reproductive issues in particular, protecting that monopoly from potential competition from the ranks of quacks, folk doctors, paramedicals such as midwives, and other so-called ' incompetents'.

For the most part, the reforms had the desired results, with some very crucial additions: the rejection of women's experiences of their reproductive capacities as emotive and not based in scientific fact; the formal marginalization of the knowledges that had heretofore served as a basis for 
women's (limited) self-control of their fertility; and finally, criminalization of practices which women had hitherto used to manage their reproductive careers, the profundity of which was compounded when, in The Queen $v$. Clarence [1889], Canadian women were denied any legal basis upon which to deny their husbands' demands for intercourse.

\section{Practical Resistance and the Growing Impetus for Reform}

Restrictive legislation did not halt abortions. Women continued to seek abortions even in the face of criminal sanction and/or onerous costs, both physical and financial. Their struggles against the medical monopoly would be waged at the level of practical struggle. In practice, women would continue to get abortions, maintain their own perception of foetal 'life', act on those perceptions, and ultimately struggle for an alternative 'common sense' interpretation of reproductive issues and the interests that should be acknowledged as legitimate in such issues (Gavigan 1986: 280).12 In these respects, many women's everyday practice - the ways in which they experienced their lives

${ }^{12}$ Whilst the hegemonic discourse of medicalization and its legal inscription dictated a view of human life commencing at conception, there is ample indication that many women continued to reject such a notion, assuming rather 'that abortion was permissible before the third month or quickening and when not induced by another person' (McLaren \& McLaren 1986: 38). Thus, women's struggles against the existing abortion prohibitions were rooted in a perception different from that advanced in the hegemonic discourse, and their actions were guided by that different interpretation. 
- was not constructed by or determined by the law. The law, quite simply, did not accord with the 'common sense' perceptions they had of their own reproductive capacities. Some members of the medical community continued to provide abortions to women when it was deemed that their lives or health might be threatened by bringing a pregnancy to term. Some even provided abortions on the basis of an expansive perception of what a therapeutic exception might entail. ${ }^{3}$ These latter were, however, few and far between. For most women prohibitive costs and uncertainty as to whether a physician, if approached, would actually perform an abortion, led to opting for self-induced or 'back-street' abortions. ${ }^{14}$ This, along with the physical dangers posed by pursuing 'back-street' abortions, and the high financial

${ }^{13}$ The medical community - at least those who would actually perform abortions for therapeutic reasons generally took 'the fact that the law prohibited abortions "unlawfully" procured' as implying legal recognition of 'lawful' exceptions (Gavigan 1986: 305).

${ }^{14}$ In these early years of 'organized' medicine, knowledge in the areas of obstetrics and gynaecology was severely limited; so much so that 'quickening was really the only way to tell whether a woman was pregnant' (Backhouse 1983: 75). The concerted internal campaign amongst 'regulars' to disavow any connection with abortion practices led to a situation where professional abortionists (usually 'irregulars') 'were most likely to be able to perform an abortion with competence and safety. In large part this was due to the experience they developed over time. compared to these, physicians who performed the procedure only rarely were often "rushed, guilt ridden, and unpractised"' (ibid., 87). Luker points out that even if physician-induced abortions were more effective, they may also have been more lethal, as they often gave rise to puerperal fever by creating sites for infection within the uterus (Luker 1984: 38). 
costs and uncertain reception women might expect to receive from doctors, may have contributed to the relative preference women displayed for self-induced abortion techniques (Gavigan 1986: 310-312).

That criminal cases regarding the definition of a therapeutic exception never came before canadian courts in these early years indicates that the medical community was considered to be largely above prosecution and suggests that legal authorities were prepared to offer the medical profession 'a wide berth to make its own rules' (Backhouse 1983: 116-117). A unique inter-professional discourse had been born through these processes, one of deference to the other's better judgement, knowledge and professional integrity.

As the twentieth century progressed, however, technological and social contradictions arose to challenge, not the medical monopoly on abortion, but a number of the positions which had originally underlain many of the technical and moral arguments that had been advanced in support of that monopoly. The end of World War II and the defeat of Nazism had largely discredited eugenics. New contraceptive technologies had been developed in the interand post-war eras and were accompanied by a new discourse of familialism, one stressing family planning. Finally, new technologies in obstetrics and gynaecology were rapidiy reducing the risks associated with childbirth, thus 
increasingly calling into question the legal viability and scope of the Criminal code provisions for the defence of necessity.

The International Planned Parenthood Federation (IPPF) began an international campaign promoting the merits of contraception as a means for both population control and family planning. Whilst not aimed at challenging medical hegemony in the area of abortion, the IPPF did argue for the need for safe legal abortions, revealing in its campaigns the extremely high levels of illegal abortion in all countries (Jenson 1990: 9). This represented an important new discursive linkage between abortion and contraception. The two had, of course, already been linked by the medical community via a threatened scourge of the underclasses. In contrast, however, the IPPF's position stressed the social merits of population control and family planning, and highlighted the immorality of death from botched illegal abortions.

Advances in medical technology achieved over this period substantially reduced maternal mortality levels. But while pregnancy and child 'birth' per se became safer by virtue of these advancements, these same improvements placed the horror of death by botched abortion in stark relief. As technology improved, those members of the medical community who had been providing the small numbers of legal (therapeutic) abortions became increasingly uneasy. 
The late 1950s and early 1960 s brought new levels of public awareness regarding restrictive abortion legislation. Along with IPPF campaigns revealing figures regarding the numbers of illegal abortions and related deaths, there were a number of media items which brought the issue out of obscurity and into full public view. ${ }^{15}$ Heightened public awareness and a concern on the part of doctors that the procedures some of them had long been performing could no longer pass the legal test of necessity, led the latter to campaign for express inclusion of a therapeutic exception in the Criminal Code's abortion provisions.

\section{The Push for criminal code Reform}

These numerous contradictions paved the way for a serious reconsideration of the ambiguous status of a therapeutic exception in criminal law. Through the $1960 \mathrm{~s}$ the Canadian Medical Association (CMA) and the Canadian Bar Association ( $C B A$ ) lobbied hard to have the existing prohibitions on abortion modified. Doctors and lawyers wanted clarification of the legal bases for a therapeutic

${ }^{15}$ The most notable of these are the 1959 Chatelaine article by Joan Finnigan, the series of editorials run by the Globe and Mail between 1961 and 1963, and the 1962 case of Sherri Finkbine who was prevented from getting an abortion in the US after having taken thalidomide during her pregnancy. 
exception in the provision of abortion services. ${ }^{16}$ With the inclusion of section 251 in the Criminal Code in 1969, they achieved just that. But, in line with the demands of the CMA and CBA, 'this was reform to define the boundaries of the legal and the illegal, not to give anyone new rights or to find a consensus about the appropriate balance between the state's responsibility for family life, through social programmes, and women's needs to control their own lives'(Jenson 1990: 24).

In contrast to much of the continental European experience with the abortion issue in this period, the Canadian changes in legislated abortion restrictions were not informed by discourses of social justice, welfare, equality and recognition of the right of women to some degree of reproductive freedom (c.f. Jenson 1987b; Caldwell 1986). Instead, in Canada the modifications to abortion legislation took place within a general discourse of liberalisation; the changes that were instituted formed a

${ }^{16}$ There is an interesting contrast between the canadian experience and that of the US on this point. It would seem that the move for abortion reform in the US resulted in a much more public rift within the medical community. Luker suggests that the move by some physicians for abortion reform led to an immediate and very vocal backlash from fellow physicians opposed to such reform, most of whom were of Roman Catholic origin (Luker 1984: 66-91). There doesn't seem to have been a parallel reaction in the canadian case. This may well be attributable to the discourse in which the respective reforms were posed: in the canadian case the focus was on the clarification and entrenchment of the status quo, whilst reform in the US was aimed at some degree of substantive change. 
part of the Liberal government's omnibus reform of archaic prohibitions on various sexual activities in the criminal Code, part of the government's campaign to 'get the state out of the bedrooms of the nation'.

At that time women had no legal status in the issue other than as patients, victims or criminals. Nor did women have any effective organizational mechanism for the insertion of demands for abortion reform into the realm of popular discourse. The women's groups that did lobby around the issue eschewed the issue of reproductive freedom for the most part, concentrating instead on the inequitable provision of existing services (Jenson 1990). Notably absent in the canadian case were the types of well-organised Left political forces that were rallying at the same time for reform of similar restrictive legislation in many European nations, but which articulated those demands within a discourse of women's (limited) right to choose the timing and limits of their reproductive careers (Jenson 1987b).

Thus, three related factors came into play to undermine any change in the legal status of women in the issue of abortion. First, the maintenance of the hegemonic discourse of medicalization coupled with a new discourse of liberalization which in no way challenged the hegemony of the former. Second, in the absence of a broader political commitment to a greater degree of reproductive freedom for women and the lack of effective social-organizational 
capacities that might have made such a commitment realizable, women's voices were rendered 'diffuse and weak during the development of the discursive compromise which established the institutions within which the practices of abortion politics occurred for the next two decades'(Jenson 1990: 8). Finally, the law had, for all intents and purposes, remained the same: women were left with essentially the same limited legal options and had gained no space within the law to viably contest medical hegemony. The only option on women's horizons at that point was the promise of a slow path to further legislated reform. As Jenson notes, the 'abortion reform of 1969 was understood primarily within a discourse of medicalization and that particular representation of the issue dominated further state interventions on the matter until 1988' (ibid., 6).

\section{In the Aftermath of Criminal code Reform}

Between the 1969 Criminal code reforms and the adoption of the charter in 1982, a number of important events occurred. In the spring of 1970, Canadian women organized the first broad scale feminist protest against the existing abortion legislation. Whilst the 'Abortion Caravan' failed to permanently cement any common discursive-ideological front amongst Canadian feminists, it did, however, provide some critical preliminary organizational links amongst Canadian women (Collins 1985: 25). 
At about the same time Henry Morgentaler began a public campaign against the new legislation, openly defying the new law by performing abortions in the office of his practice in Montreal. As the years progressed, Morgentaler expanded his provision of services to other major Canadian centres, challenging local, provincial, and federal opposition.

With regard to the Morgentaler saga three points are important for our purposes. First, Morgentaler was acting in direct contravention of the law rather than permitting the law to dictate his practice. Second, Morgentaler's conflicts with the law pushed the abortion controversy into popular discourse in a way in which it had not appeared previously. ${ }^{17}$ Third, Morgentaler's confrontations with the law served as a lightning-rod for a budding second-wave Canadian feminist movement. ${ }^{18}$ Whilst it would clearly be inappropriate to attribute organized interest in the abortion issue to Morgentaler alone, the public controversy spurred by his opposition to the law did, in many ways,

${ }^{17}$ Morgentaler was pushing not only for greater legal latitude in a physician's decision that an abortion was necessary, but also maintained a very vocal dedication to a woman's (limited) right to choose whether or not to abort.

${ }^{18}$ As the Morgentaler saga unfolded, there developed around it 'a broad-reaching coalition of doctors, members of family planning associations, CARAL, Trotskyists, anglophone feminists, and the women's commission of the quebec Teachers' Union' (Jenson 1990: 35). 
provide a useful point of reference for many of these groups to publicize the inequities of the existing legislation. ${ }^{19}$

Another factor that intervened in the years following the Criminal Code revisions of 1969 was the emergence of universal health care. As health care provisions were presented to the public as being a basic social right, women in many parts of the country were finding that they did not have equal access to safe, legal abortions. The legal requirement that any decision to abort was to lay in the hands of a therapeutic abortion committee translated, in practice, to an absence of abortion services to women in many parts of the country as many hospitals simply refused to establish committees. Furthermore, some of those that did establish committees took a very strict interpretation of the 'necessity' for abortion in individual cases. The result was terribly unbalanced access to abortion across the country. As Gavigan points out, 'the paradox ultimately resulting from the recognition of the therapeutic exception was that it led to greater uncertainty and inequality of

${ }^{19}$ Unfortunately, many authors have tended to reduce the abortion controversy in Canada to the confrontations between Morgentaler and the law (see for instance campbell and Pal 1989). Whilst these sorts of analyses are useful insofar as they highlight important events in the evolution of the controversy, they fail to appropriately situate the vital role that women's opposition to the status quo played in the unfolding of events. Furthermore, it should be noted that some women's groups did take offence at the association of the issue of abortion rights with that of doctors' rights. It was on the basis of this latter criticism that the centre des femmes in Montreal disassociated themselves from the Morgentaler campaign (Jenson 1990: 35). 
access to abortion, so that in practice there was one law for the rich and another for the poor' (Gavigan 1986: 310). The problem of unequal access to health care services was to become a focal point for the pro-choice movement.

In 1973 the United States Supreme court (USSC) decided Roe v. Wade. Prior to this case many states had had legislation which severely restricted abortion service provision. In Roe, however, the USSC decided that such legislated restrictions constituted a violation of a woman's constitutional right to privacy. This decision is important for our discussion for a number of reasons. First, it opened a door for Canadian women who needed safe abortions and could afford the journey to the us to get them. While this served as a relief valve for those canadian politicians who would rather not deal with the issue, the journeys south also began to point up the dualistic nature of availability of abortion services in Canada. Poor women, often immigrant or native, were unable to afford such services and, lacking services at home, were forced to get back-street abortions, self-induce, or carry unwanted pregnancies to term. Second, the discourse in which the Roe decision was couched was that of rights: more specifically, a right to privacy. ${ }^{20}$ Third, for the first few years following the decision, abortion

\footnotetext{
${ }^{20}$ This was arguably significant in that it ultimately led to the decision in Harris v. McRae in which the USSC argued that because abortions rights are private rights, there was no basis for the claim that the state need provide funding for such procedures.
} 
could, at least in the first two trimesters, be posited as a woman's right. discourse of medicalization that had so long dominated the politics of abortion in the US.

Finally, another actor came on the stage in the intervening years between the 1969 Criminal code revisions and the 1982 entrenchment of the charter: the right to life movement (Collins 1985: 1-12). Particularly important here is the discourse within which the right-to-life challenge has been posed: that of the rights of the foetus.

The first major response from the government to this new multitude of social forces came with its establishment of the Badgley Commission in 1975. In terms of its recommendations, the report accomplished little, suggesting that the existing law was fine and that it was, rather, the way in which those laws were being implemented that was problematic. But the commission did serve two very critical functions. First, it highlighted the existing inequities in the provision of abortion services across canada. This was crucial insofar as it provided a government sanctioned public recognition that the criminal code revisions of the previous decade had done little in terms of creating equality of service provision for Canadian women seeking abortions. ${ }^{21}$ Second, it served as an additional focus for

${ }^{21}$ This is not to suggest that the ultimate report reflected the incumbent Liberal government's perception of the issues, but rather, that the commission itself was state 
the organization of women and further opened up space for a public articulation by women's groups of abortion as a women's issue. Its recommendations were, however, couched in the old terms of abortion as an unfortunate bi-product of inadequate education of contraceptive techniques and proposed a more pro-active role for government in 'family' planning.

Hitherto, women's struggles for reform of existing laws restricting access to and provision of abortion services had focused on legislative and administrative reforms. Women were constrained by the formal institutional matrix of the state in which the only avenue for legitimate contestation of existing social relations was through legislated revision of women's positions vis-à-vis reproductive issues. The advent of the charter of Rights and Freedoms in 1982, and the political struggles that surrounded its specific provisions, profoundly altered the political process in Canada. Its passage changed the political landscape by opening new 'legitimate' discursive space for women (and other groups) to press their political claims. Whereas alternative discourses had previously been consigned to political invisibility, left to challenge the parameters of the prevailing universe of political discourse through legislative and administrative channels, the charter and its 
guaranteed rights and freedoms provided a new strategic terrain upon which such claims could be pressed.

By the time that it became apparent that a charter would be included in the proposed constitution Act women's groups had managed to develop a formidable organizational capacity. But there was a lack of unitary vision: the women's movement generally proved to be both 'divided... [and] heavily weighted towards liberal feminism. Equal opportunity and individual rights claims have dominated the agenda of this [liberal] wing of the movement since the middle 1960s' (Jenson 1990: 35). The equal rights focus of the Canadian women's movement tended to stress a degendered equality, placing primary emphases on the need for women to gain equality of opportunity in the workplace. The result of this strategy has been a tactical decentring of reproductive issues and the marginalization of a politics of difference: the fact that only women bear children would have to take second seat to women's needs to achieve a degendered equality.22

${ }^{22}$ This is not to suggest that issues of gender are necessarily occluded by liberal approaches to equality. Rather, liberal feminist marginalization of reproductive issues has been much more a matter of focus and stress. As Jenson points out:

... in its assessment of the ten years after the Report of the Royal Commission on the status of Women the [Canadian Advisory Council on the status of Women] places more stress on the 'new issues' up-coming in the 1980s - women's special needs in the labour market, equality in social programmes, overcoming sexist attitudes, etc than on reproductive rights. The National Council of 
But whilst the feminist voices that spearheaded the sexual equality provisions ultimately enshrined in the Charter were couched squarely within a particular variant of liberal equality rights discourse, the vague and ambiguous wording with which those rights were articulated has left wide space for more expansive alternative interpretations of their meaning. Such interpretations will depend largely upon broader societal struggles over what precisely notions such as freedom and equality mean. Considering law in these terms we see not only that it is central to any political strategy aimed at social change, but also that law and legal interpretation are permeable to broader social struggles. Law also reacts back upon those struggles, largely by defining the boundaries of what can legitimately gain expression within. law's terms.

In the years since the charter's adoption numerous struggles have been waged over just what its provisions should mean for women. One important area of contestation has been the struggle over a woman's right to choose whether to abort a foetus or carry it to term. This struggle was,

Women, the oldest and largest women's rights group in the country, did not present a resolution on reproductive rights or abortion to its 1983 Annual Meeting ... In a very wide-ranging list of concerns of the 1980 s women's movement reflected in the recommendations made to the MacDonald Commission by women's organizations references to reproductive freedom, to reform of the abortion law, or to any version of the demand for women's control over their bodies were absent. 
however, carried on within the terms of the hegemonic discourses of liberal individualism and medicalization. In other words, abortion and other reproductive issues were still deemed medical issues at law; only doctors had the legal power to make decisions in these areas. Whilst potential new spaces for the contestation of existing social relations were opened up by the charter, the substance of those contests was shaped by the formal constraints of the law until such time as new space could be opened by the creation of a breach in the hegemonic discourses. Just such a breach occurred in January 1988 when the supreme court of Canada struck down section 251 of the criminal code in its entirety.

\section{Morgentaler and Beyond}

In Morgentaler [1988], the court decided that the provisions of section 251 of the criminal code constituted a violation of a woman's right to life, liberty and security of the person as guaranteed under section 7 of the charter. This decision was absolutely vital for women: for the first time in the history of Canada women were granted formal space in the legal debate surrounding abortion. It would be incorrect to suggest that such a result could not have been achieved through other political means (i.e. through legislative reform), but if history is any indicator it would suggest that such a strategic route would have been 
much slower, particularly whilst mainstream Canadian feminism remained couched within a predominantly liberal discourse which tended to decentre reproductive issues. But as shelley Gavigan has pointed out, the victory that Canadian women achieved with the Morgentaler decision was 'fragile, incomplete and contradictory' (Gavigan 1990: 2). Not only did women gain potential new space as legal contestants in the debate over who can legally decide whether or not a foetus might be aborted, but a host of other potential combatants were also thrown into the fray. Most explicitly, the court recognized that the state might have some interest in the welfare of the foetus. The court, however, deemed this to be a question that must be resolved in the legislatures, thus tossing the 'moral' ball back into the politicians' court.

There are a number of factors that have come to the fore in recent years that are likely to impact on any resolution of the abortion issue, and the competing rights claims that have arisen around it. There have, for instance, been a number of 'advances' in reproductive technologies in recent years that have and will continue to shape the way people think about issues such as pregnancy, when life begins, the status of the foetus, etc.

First, there is the issue of foetal viability and the popular myth that somehow medical technology will continue to reduce the gestation period necessary for extra-uterine 
maintenance of foetuses. In recent years great strides in pre-natal technology have shifted the nature of the debate in such a way that the myth of extra-uterine viability has gained new ideological purchase. ${ }^{23}$ Second, there are new discourses of humanization and personhood which surround the foetus. Led by a proliferation of new pre-natal technologies, the foetus has become represented discursively and visually as autonomous from its mother (Rothman 1989 122-124; Petchesky 1990: xii-xvi). ${ }^{24}$ Third, a discourse of infertility led by new reproductive technologies - such as

\footnotetext{
${ }^{23}$ As Petchesky points out, '[m]ost authorities agree the extra-uterine techniques for sustaining fetuses of earlier than twenty-four weeks' gestation (600 grams) will not be achieved in the near future, if ever' (Petchesky 1990: $\mathrm{xV})$. The pervasiveness of the myth is, rather frighteningly, highlighted by United states supreme court (USSC) Justice Sandra Day O'Connor's declaration in Akron V. Akron Centre for Reproductive Health, Inc. that Roe $\mathrm{v}$. Wade was on a technological collision course with itself. The clear assertion here is that the American judiciary perceives as likely continued progress in pushing back the limits of foetal viability. Given, however, the fact that foetal viability has not been dramatically altered in recent years (in contrast to the intimations contained in this decision) it would seem prudent to look elsewhere to determine how such notions have attained potent purchase in popular and legal discourse. The foetal images campaigns, the rightward shift in political discourse, and dissemination of right-to-life rhetoric would seem potentially fruitful avenues for investigation of these issues.

${ }^{24}$ These new technologies include amniocentesis, sonograms, ultra-sound, and in utero surgical techniques. An important spin-off of these technologies is the early determination of foetal sex that they have made possible. The latter seems to have signified a new turn in the intensity over the issue insofar as it further' dethingifies' the foetus, rendering it, rather, a 'gendered person' at as early as twelve weeks gestation.
} 
in vitro fertilization and surrogacy techniques - have had a negative impact upon the pro-choice movement, thrusting another identity into the fray: the 'barren' woman (Rothman 1989: 140-151). Women who choose to abort foetuses seem selfish and heartless in the face of an apparent rise in infertility and a concomitant 'baby dearth'. Right-tolifers' contentions that all 'babies' are wanted babies gain additional purchase from the popular perceptions that, increasingly, many who desire children cannot have them. 25 Finally, improvements in post-coital contraceptive technologies and their proposed commercial introduction has both changed perceptions of the ease and nonchalance with which women can reject embryos, and has injected new vigour into debates over when precisely life begins.

But it would be a gross overstatement to suggest that only technology has fuelled this backlash; these events have also arisen in the context of a reinvigoration of androcentric culture. The eighties gave rise to the New Right 'revolution' in Canada, the US and Great Britain.

${ }^{25}$ In actuality there has been no rise in the infertility rate; rather, technological advance and media preoccupation have converged to construct a perception of fertility crises. Not only has there been little indication of a genuine rise in infertility, but there is also evidence to suggest that many couples who seek fertility treatment have already adopted children ('Centrepoint Documentary' CBC Sunday Morning, December 23, 1990). An alternative interpretation might be warranted here: that many such women's perceptions of themselves as complete women have been centred around the discursive construction of the identity of 'real women' with motherhood and the bearing of children. 
These 'revolutions' have largely focused on a re-assertion of traditional (patriarchal-christian) family values and a concomitant rejection of abortion and militant feminism as antithetical to those values (Petchesky 1990: 241-276). Furthermore, this 'right-turn' has been a major contributor to rendering empty the promises of formal legal equality that women had fought so hard and so long to achieve, a move which smart has pointed to as evidence of the emptiness of formally successful rights claims (1989: 152).

Thus, while the Criminal code provisions of 1969 formally maintained the hegemony of the medical community over women's choices in the abortion issue, innovation in reproductive technologies, the rightward shift that prevailed in the hegemonic political discourse of the eighties, and the everyday practices of women attempting to take control of their reproductive lives have all, to some extent, undermined the social bases of legitimation of that legislation. But these observations hold, generally, for the American and British cases as well. A closer examination of the historical specificity of the canadian case reveals that the evolution of the debate in canada was unique in many respects. Perhaps the most important point of divergence arose out of the process of constitutional reform that Canada has undergone in the last decade. ${ }^{26}$

\footnotetext{
${ }^{26}$ There are other major points of divergence. For example, the American case has not evolved within a discourse of social rights to universal health care
} 
The struggles which have arisen around the charter have resulted in the insertion of 'women' as a legitimate collective actor in the politics of abortion. Where women were once limited to pursuit of legal reform through everyday practical struggle and legislative reform, the Charter opens up a new range of strategic possibilities, both negative and positive. Now women can go directly to the courts to pursue their political objectives or, conversely, can be called upon by the courts to defend their interests in specific issue areas.

Thus, the charter and the struggles surrounding its formulation have served to shift the institutional form through which the politics of abortion might take shape. But, what the foregoing should suggest is that 'law' has always played a central role in restricting women's access to abortion. Law has also constituted the form through which struggles for legitimate, state-sanctioned, noncoercive control over such access have been played out, whether by doctors or women. This is not to suggest that law is the only site of struggle. Indeed, for women the law surrounding the abortion issue has only recently been opened to pro-active struggle. Women's struggles for control of

provision. At the same time the British experience has been one that did not include issues of codified rights and freedoms - something that did exist in the American case, albeit in a fundamentally different context from that which emerged in Canada. 
their reproductive capacities had long been relegated to legal and political obscurity by their exclusion at law. Insofar as the issue of abortion is concerned, the shift which has occurred in women's relationships to the law cannot be dissociated from the contradictions that arose out of women's everyday practices in continuing to seek abortions, women's struggles for equality in other areas of their social relations, the shifting nature of reproductive technologies, doctors' concerns over their own legal status in the issue, and shifting public attitudes towards sexuality. only a more complete sensitivity to these dynamics will help us understand more fully the forces that have thrust abortion into the public consciousness in recent years.

\section{Summary}

By way of summary, this chapter has attempted to highlight the important role law has played throughout the evolution of the abortion issue in canada. Law has not been wholly determinative of women's practices, but nor has it been impervious to the contradictions raised by those practices. It has, however, placed very real formal constraints on the range of political options women have had at their disposal to contest the regulation of their reproductive capacities. Perhaps most importantly, law has only admitted of specific identities as valid interlocutors 
in contesting issues related to abortion. Women, interested in exercising some modicum of control over their fertility, have not, for the most part, constituted one of those identities. 


\section{Chapter II}

\section{Juridification Tendencies in Advanced Capitalism: The Legalisation of Politics in Canada}

As was noted in chapter one, the advent of the charter of Rights and Freedoms in 1982, at least to some extent, opened the way for women to contest aspects of the legal regulation of their fertility. Women, of course, have not been the only ones to use the new charter as a mechanism for change. Since that time many social movements have decided to test whether or not the Charter's provisions might be applied to their social circumstances and, in turn, provide a mechanism whereby they might achieve redress for their specific grievances. To do so they have invoked the Charter's provisions in an effort to both advance and legitimate their political objectives. ${ }^{1}$ At the same time, however, such legal challenges have often met with limited, if any, success.

Whether or not the charter should be seen as a mechanism to effect social change has been the subject of an ongoing and heated debate in canada. This chapter focuses on one influential canadian attempt to understand the advent of the charter in terms of both a domestic and, more broadly, international trend toward juridification. The

\footnotetext{
${ }^{1}$ Numerous groups have engaged the charter's provisions in this way. In his recent book, Mandel (1989) discusses a plethora of such cases involving such disparate social interests as those of ethnic groups, abortion and antiabortion rights groups, peace groups, and workers.
} 
adoption of an entrenched charter and concomitant tendencies in recent years to attempt to resolve political conflict in the courts is what Glasbeek and Mandel describe as the 'legalization of politics' (1984²; C.f. Mandel 1989; Fudge 1988, 1989). This formulation suggests that capitalist societies are currently undergoing a drift toward a new brand of politics: political struggles in late capitalism are being pushed out of more traditional democratic fora and into the arena of the courtroom, as the state and/or capital respond to the need to secure broad social legitimation in an era when reliance on the traditional democratic - i.e. legislative - sources of legitimation pose problems for capitalism's continued reproduction.

Whilst the following represents an almost complete rejection of Glasbeek and Mandel's theoretical position and, in turn, of their political prescription regarding the role of law in progressive struggles, a consideration of their work in the context of the current study seems important, for a number of reasons:

- first, their position is couched squarely in terms of an expansion of the influence of the judiciary and the growing social significance of legal form. In other words, it quite readily falls in with those lines of criticism that posit what I have loosely termed here 'juridification theses';

- second, their theoretical framework provides the foundation for a political prescription - that progressive social forces avoid the 'false appeal'

${ }^{2} \mathrm{All}$ references in this chapter are to Glasbeek and Mandel (1984) unless otherwise specified. 
of formal legal rights - and in these terms alone their position warrants serious scrutiny;

- third, the failures of their approach highlight just how limited some variants of marxist thought are in attempting to come to terms with issues not reducible to class or economy;

- fourth, in the course of their analyses they draw on a large body of case law to provide an empirical basis to their theoretical position. This body of cases highlights the fact that law is often limited, or perhaps even a potentially regressive mechanism for the stimulation of progressive change; and,

- finally, the abortion debate, as it has been played out in both Canada and the US, is drawn on regularly as an empirical referent in their analyses.

This chapter is divided into three parts. The first outlines Glasbeek and Mandel's theoretical argument whilst the second advances a critique of their position, both its theoretical and methodological aspects. Finally, the third part examines their treatment of the abortion issue and endeavours to draw out what their position might have to offer an analysis of the politics of abortion in Canada.

\section{The Roots of Legalized Politics}

For Glasbeek and Mandel, the legalization of politics in Canada can be traced to a number of sources which the authors seem to divide into two general categories. The first of these deals with the specificity of the experience of post-war Canadian political economy. The second attempts to situate the Canadian experience within broader tendencies toward legitimation and accumulation crises in advanced capitalism 
Glasbeek and Mandel suggest that the first real push toward legalized politics in Canada - i.e. an entrenched bill of rights - arose in the years immediately following the second World War. Part of the impetus for such a transformation in the role of law in western societies arose out of an expressed desire amongst western nations for some recognition and declaration of human rights in international law in the wake of the atrocities of the war (pp.84-85). But Glasbeek and Mandel suggest that there were three other factors that were probably more important to the post-war push toward legalized politics in Canada. First, there was a fear of a 'new despotism' spurred on by a libertarian reaction to western governments' heightened involvement in the market and social management during wartime. Second, there was the perceived threat of insurrection posed by the threat of collectivist/ communist ideologies of nontraditional immigrant groups (pp.85-86). Third,

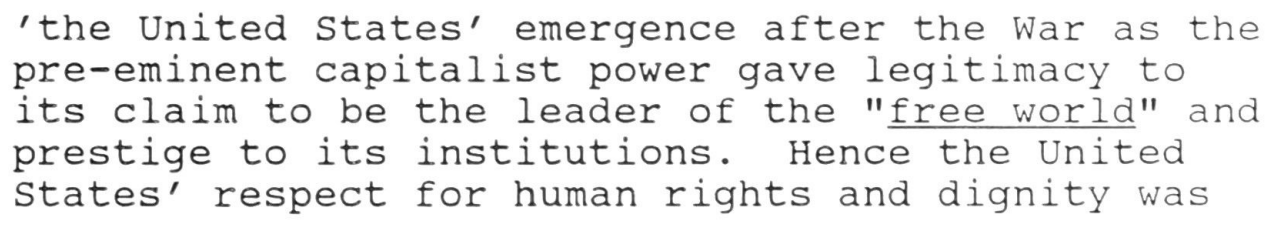


unquestioned and, in the mind of the legal profession at least, attributed to its entrenched Bill of Rights. ${ }^{3}$

Thus, Glasbeek and Mandel see postwar libertarianism, anticommunism and the appeal of constitutionally entrenched rights in keeping with the American model as the most important early bases of a move towards legalized politics in Canada."

The major impetus to the 'legalization of politics' in Canada came with the adoption of the Canadian Bill of Rights and the refusal of Canadian courts to take an expansive view of the rights enshrined therein. ${ }^{5}$ Moreover, Pierre

'Interestingly, the 'Americanization' of the Canadian judicial system is a constant thread running through Glasbeek and Mandel's project (c.f. Mandel 1985, 1989). This theme is not, however, adequately developed and the reader is left wondering whether 'Americanization' is bad because it's American, because America constitutes the great bastion of liberalism and capitalism, or because they see it as another chip in Canadian institutional autonomy. For a liberal critique of the Americanization of Canadian law see Cheffins \& Johnson (1986).

${ }^{4}$ Glasbeek and Mandel look to the antistate/administration, anti-communist rantings of Judge C.H. o'Halloran, and the latter's seeming devotion to the style of rights and freedoms protections provided US citizens as a good example of just how much freedom and liberty was really contemplated by the legal elite in Canada in the formative years before the introduction of the Bill of Rights.

${ }^{5}$ Thus in cases like Attorney General of Canada $v$. Lavel1 [1974] the Supreme court of Canada refused to take an expansive reading of equality rights. In that case the court refused to strike down those parts of the Indian Act which stripped native women of the right to maintain their native status if they married outside of the native community. The Act, it was argued, was discriminatory because, while it stripped women of their status, the same rules did not apply to native men who married outside the 
Trudeau's arrival on the federal political scene brought with it a new agenda for constitutional reform. Key to this agenda was an entrenched bill of rights which would include language rights for both Canadian charter groups, a move which would serve two objectives: first, Trudeau believed that entrenched language rights were crucial to any political strategy which aimed to thwart growing separatist tendencies in Quebec (Trudeau 1968: 52-60) and, second, it would meet the courts' challenge to give such a bill constitutional weight.

Finally, in their quest for the roots of legalized politics in Canada, Glasbeek and Mandel look to global events in the late 1970s, a period which 'saw the onset and intensification of the current crisis of world capitalism, a factor which we consider a catalyst for the process, even though it was not mentioned in any government documents'(p.89). Drawing on a number of theoretical sources they suggest that states experience mounting accumulation and legitimation crises in the monopoly phase of capitalism. Such crises stem from the state's increasing attempts to intervene to ameliorate what would otherwise be

native community. In this case the supreme court decided that, in the absence of an entrenched bill of rights, it was beyond the jurisdiction of the court to overturn the relevant legislation. In these terms, the court's refusal to take an expansive approach to the Bill of Rights was seen as a call for the government to 'put up or shut up' (Glasbeek \& Mandel: 89). That is, if the government wanted a bill with teeth, such rights would have to be entrenched in the constitution for the court to take them seriously. 
the socially devastating impacts of unfettered market forces. In this process states actually take over some of the accumulation functions formerly the sole province of capital. Responding politically to the social contradictions that arise out of this blurring of the division between the public and the private, states and capitals must avoid recourse to genuinely democratic sources of social decision-making if the reproduction of accumulation is to be secured.

In order to ensure accumulation and deal with the mounting fiscal crises that attend the monopoly phase of capitalism the state must develop methods of ensuring legitimation. This entails a move from democratic forms of legitimation to non-democratic forms - i.e. from bourgeois universal suffrage to bourgeois legalized politics. As such, the mystificatory nature of the legal form renders a full appreciation of the genuinely oppressive nature of law and rights beyond the grasp of the general populace by masking real social relations of oppression and providing the latter with popular legitimacy. The likelihood that the judiciary would adopt decisions favouring the underclasses and the oppressed is rendered effectively nil by the fact that judges and lawyers come from and represent the interests of the ruling classes. Lawyers and judges have 
high incomes and as such have interests that are indistinguishable from those of capital.6

For the authors, it is the form of legalized discourse that gives rise to the mystificatory potential of law. For them, formal rights, like those guaranteed in the charter, tend to mystify the reality of oppressive social relations. This mystification stems from two sources: the individuating effects arising out of the abstract nature of liberal conceptions of individual rights, and the derivation of the legal form from the commodity form. In developing their

${ }^{6}$ Elsewhere, Mandel has rhetorically posed the question 'Is the charter in any way going to enhance democracy?', responding with a flat 'No!'. How can it when '[l]aw students come "disproportionately from the wealthier classes of societies". Lawyers are the wealthier classes, with healthy representation in the economic and political elite' (Mandel: 3). Lawyers and judges make huge amounts of money, far higher than the national average income. This in turn leads to an 'inevitable class bias' on the part of the members of the legal profession (ibid.: 43). Because of this bias, attempts by the occasional, exceptional renegade member of the profession to challenge the status quo are doomed to failure: 'When the legal profession opposes powerful [capital] interests, we know who is going to win' (ibid.: 246).

It is not clear whether or not the authors mean that income levels actually constitute members of the legal profession as capitalists (i.e. class is dictated by income), or whether their position is underlain by an assumption that the interests of those in the legal profession are somehow necessarily identical to those of capital. Judges, as representatives of the capitalist state, are presented as speaking in much the same voice as capital, a voice that is particularly dedicated to liberal loathing of government intervention in market and other 'private' aspects of society. For instance, they advance the politics of Judge O'Halloran some 45 years ago as constituting a clear example of the congruent interests of the judiciary and the capitalist class (85-86, 96-97; c.f. Mandel: 9-14). 
theoretical position on these two items the authors draw upon the liberal jurisprudence of Ronald Dworkin and then the marxist legal theory of Evgeny Pashukanis.

The authors orient their discussion of the nature of the legal form around the issue of what it is that distinguishes judicial reasoning from legislative reasoning. The answer they find in Dworkin is, simply, that judges restrict themselves to retrospective considerations of legal principle. Legislators do this too, but their professional tasks include forward looking, innovative policy considerations. Arguments of principle are 'intended to establish an individual right' (Dworkin as cited at p.104; emphasis added), one that is to be defended against incursions by the majority. Arguments of policy, on the other hand, 'are arguments intended to establish a collective goal' (ibid.; emphasis added). Legal discourse, in the process of judicial review, thus serves as a mechanism for legitimating political discourse; it provides a different legitimatory basis for political decisions $(\mathrm{pp} .103-104)$

But it is not the retrospective principle of stare decisis that makes rights discourse necessarily conservative. Nor do the authors feel that it is the preference expressed in rights discourses for individuals over collectivities. Whilst these, the authors contend, are both very real problems with rights discourse generally, 
they are 'all effects of a more fundamental aspect, namely the abstract nature of the permitted principle type of justification, as opposed to the concrete nature of the forbidden policy type of justification'(p.106).

The authors accept Dworkin's conception of rights, and marry this analysis with an appropriation of aspects of Pashukanis's work. They employ Pashukanis in an effort to derive a conception of the notion 'rights' from their genesis in the commodity form. The abstract nature of that form 'demands that there be a total absence of all forms of coercion, except those based on class and history' (p.107).

Glasbeek and Mandel do not, however, limit their argument to theoretical exercise. Rather, they engage in a sort of legal empiricism, piling up a number of cases upon which they ultimately hinge the veracity of their theoretical claims. In their estimation legalized discourse poses a number of problems for progressive forces that might attempt to usefully exercise formal rights. First, historical experience with constitutionally entrenched bills of rights - i.e. the US experience - indicates little likelihood that such bills' provisions might be used for progressive ends. Second, if progressive victories are had at law, progressive social forces are usually unable to enforce their content, rendering such victories devoid of substance. Worse still, they suggest, is the fact that conservative social forces are often able to turn formal 
legal advances to their own ends, using them against progressive interests. Third, and finally, judicial review of the kind contemplated by the legalization of politics thesis is fundamentally anti-democratic.

The authors suggest that the failure of legal 'victories' to provide substantive remedy to social inequalities and injustices points up the bankruptcy of formal rights. The authors point to the historical experience with a constitutionally entrenched bill of rights in the US and suggest that this experience indicates that there is little likelihood that such bills' provisions might be used for progressive ends.

The upshot, then, of Glasbeek and Mandel's legalization of politics thesis is that it comes along with a political prescription: progressive social forces aiming to effect substantive social change should not succumb to the false allure of the formal rights contained in the charter. Insofar as it does explain progressive victories, such victories are put down to the seeming inevitable cooptation of subordinate classes and social movements into the mechanisms underlying their very subordination. In Glasbeek and Mandel's words:

... history tells us that there will be many more losses than victories. And, for judicial victories to become concrete gains, legitimacy must be accorded to the judicial process in general. Thus, each isolated victory legitimates the inevitably greater number of losses which will be suffered by the working class. 
As such, legalized politics and, more generally, law are instruments of class domination whose function is to legitimate such domination.

\section{The Legalization of Politics and the Politics of Abortion}

As was noted above, Glasbeek and Mandel rely on the US experience with constitutionally entrenched rights to glean some insight into what the entrenchment of formal rights in Canada might portend for progressive social forces. They look to the history of two crucial American abortion cases - Roe V. Wade [1973] and Harris V. McRae [1980] - as classic examples of the inability of formal rights to take into account history and class (pp. 95, 97, 108-109; cf. Mandel 1989: $275 \mathrm{ff.}$, and passim).

For them, the progressive victory attained in Roe did little more than galvanize opposition to the ruling. ${ }^{7}$ They argue that a preferable strategy to the one pursued by prochoice forces in $\underline{\text { Roe }}$ would have 'consisted of ordinary political efforts to repeal abortion laws on a state by state basis... At least this would have avoided confusing

7In Mandel's recent book (1989) he cites a passage from New Republic which seems to capture his own feelings about the decision in Roe. That article suggested that Roe v. Wade was 'the worst thing that ever happened to American liberalism. Almost overnight it politicised millions of people and helped create a mass movement of social issue conservatives that has grown into one of the most potent forces in our democracy' (Mandel 1989: 288). Presenting this as a reasonable assessment of the import of Roe, Mandel goes on to imply that Roe was largely at the root of the failure of the ERA and the election of Ronald Reagan (ibid.: 289). 
the abortion issue with the different one of democracy versus "government by judiciary"'(p.97). Such a state-bystate campaign fought out in such traditional democratic fora as state legislatures would have been far superior to giving added legitimation to an anti-democratic institution like the US supreme court.

The authors suggest that the 1977 Congressional passage of the Hyde Amendment and the subsequent confirmation of its terms in Harris stand as classic examples of the ways in which the legal form 'holds class entirely irrelevant'(p.108). Where Roe upheld a woman's right to choose to abort or not, the Hyde Amendment, in placing the abortion procedure out of reach of many poor and minority women, rendered the dubious victory of Roe empty of progressive potential.

Glasbeek and Mandel's original article (1984) came four years before the decision in Morgentaler [1988] and offers no substantive discussion of the situation that Canadian women faced in the pre-Morgentaler years. In his recent book, however, Mandel devotes a good deal of space to examining the abortion issue in Canada (Mandel 1989: 273 ff., and passim) but it is not clear that his analyses add much to those of the earlier article. His treatment of the abortion issue is perhaps best summed up in the following quote:

To be recognized under the charter, struggles must take an abstract, classless form. Otherwise the 
judges will run the other way. They must take a form that does not challenge the material basis of social power. They must leave that kind of power intact. The repeal of the abortion law, considered on its own, is that kind of issue. It moves the state out of the field, leaving it to the system of private power. That is why it could be united ... with extra-billing and the NCC. Although it may offend some powerful people... the appeal of the abortion law does not actually injure their interests. It simply privatizes the question. Like the Post office.

(ibid., 301-302)

Mandel focuses on the fact that Morgentaler has not remedied the distribution of abortion services to canadian women, pointing out that access to abortion is still skewed in many parts of the country according to a woman's class position. And while he does call the repeal of the abortion law that came with Morgentaler 'perhaps the only unqualified good result to come from the supreme court of Canada yet' (ibid., 287; emphasis added) he goes on to suggest that 'we have the charter to thank for the delay in reforming the abortion law and the uncertainty of the outcome [of Morgentaler)'(ibid., 295). He points to the effective decriminalization of abortion in the province of Quebec long before the charter or the Morgentaler case that ultimately overturned the criminal code restrictions on abortion.

\section{The Legalization of Politics: An Assessment}

There are a number of problems with Glasbeek and Mandel's formulation, each of which serves to undermine the cogency of their juridification thesis and to seriously call 
into question their treatment of the abortion issue. I will not attempt here to systematically critique all aspects of their position as such an endeavour would lead me away from the two key themes of this paper: the apparent tendencies toward juridification and how these might be interpreted by progressive political forces. I will therefore restrict myself to three key aspects of their position, two theoretical - essentialism and economism - and the other methodological - ahistoricism.

Glasbeek and Mandel see the advent of the charter as one manifestation of a broader tendency in advanced capitalism toward the use of formal rights as a functional mechanism for the legitimation of prevailing social power relations. The reason why the legal form can function this way is because of its abstract essence, an essence which cannot permit of issues related to history or class (passim; c.f. Mandel 1985, 1989). This essence arises out of law's basis in the commodity form and its concomitant tendency to individualize subjects.

Much of the problem with this formulation derives from the authors' effort to wed Pashukanis with Dworkin without critically assessing the limitations contained in each before-hand. Given that their critique of the legal form and, in turn, of formal rights, arises out of this questionable marriage, I will begin here and work my way 
back through their broader critique of the legalization of politics.

The authors seem to ignore the broad-ranging critiques that have been levelled at the most reductionist aspects of Pashukanis's work. For Pashukanis 'the essence of law in capitalist society is to be found in its distinctive form, that of rights and duties of individual legal subjects equal before the law. This form of law is the direct juridical analogy and necessary fulfilment of commodity form' (Cotterell 1984: 124). Such analyses have been absolutely critical for a marxist understanding of law, its bases in social relations and the constraining effects that these bases might have on subsequent efforts to appropriate law for radical purposes. But form-derivation analyses come along with a variety of essentialist prescriptions, none of which are wholly tenable once the inadequacies of this approach are seriously considered.

As Roger cotterell has pointed out, the major defect of commodity-form reductionist accounts of law is that 'in reducing legal form to commodity form it stresses only one of perhaps several determinants of legal form, and so underestimates the diversity of legal doctrine and the possibility of adaptations and variations in the forms of western law'(1984: 125). Thus, 'commodity-form theories of law cannot handle the weight and variety of law in the modern interventionist state' (Sumner 1983: 151). Form 
derivation (along with other reductionist forms of analysis) tends to ignore 'the contradictions and tensions which derive from other social forms ... and the antagonisms constructed around them are overlooked' (Jessop 1990: 333). In contrast to such a position, any adequate analysis of extra-economic orders

must either develop [its] own concepts for analysing the internal dynamic of these extraeconomic orders and/ or borrow them from these orders themselves or from other disciplines. For they cannot be logically derived from the nature of capitalist economic relations. Nor can one simply assume that all social relations in capitalist societies will somehow "correspond" to the reproduction requirements of capitalist economic relations.

(Jessop 1990: 332; emphasis added)

Thus, Glasbeek and Mandel's account lacks any recognition of the inherent limitations of form-derivation. But, working back through their analysis of the origins of juridification in advanced capitalism (and specifically in the canadian case) we can see that form-derivation constitutes the keystone for a debilitating essentialism in their analysis of 1 aw. ${ }^{8}$ The authors contend that it is this essence of legal form (derived from the commodity form) which lies at the heart of the individuating effects of law

${ }^{8}$ By essentialist analysis I mean any account of the mechanisms of social oppression which traces their origin and form to a single essence, to the exclusion of a recognition of the multifarious complex nature of social relations. Moreover, as a form of reductionism it also incorporates an element of determinism insofar as that core essence limits or constrains the range of social potentialities, naturally favouring some outcomes whilst precluding the possibilities of others. 
identified by Dworkin. Moreover, it forms the basis of the policy/goal-principle/right distinction which they find so useful in Dworkin's work.

This essentialism, however, precludes any recognition of the limitations inherent in Dworkin's conception of rights and goals. Their essentialism keeps them from seeing precisely that it is not some pre-given essence of legal form that must be opposed, but rather, it is the very dogmatism of liberal conceptions of right such as those propounded by Dworkin which must be subjected to critique and transcended.

Glasbeek and Mandel's essentialism is paralleled by a more general and pervasive economism ${ }^{9}$ throughout. This appears in their reduction of all struggle to class struggle. The assumption that law occludes only relations of class and history begs the question 'Why only class and history?'. Such an approach fails to recognize that the

'I am using a variation on Roger simon's conception of economism here. Simon defines economism as:

the interpretation of Marxism which holds that political [and legal] developments are the expression of economic developments; the line of causation proceeds from the economy to politics [and law] which [tend] to be deprived of any autonomy. One form of economism is the view that history possesses a necessary movement, independent of the human will, derived from the continual growth of the productive forces. Capitalism is seen as developing inexorably towards economic crisis and collapse as the contradiction between the forces and relations of production become greater. 
legal form can (but need not necessarily) occlude other social relations of domination and subordination that, whilst ultimately necessarily articulated with class, are in no way reducible to the latter.

The problem with this class-centricism is that it does not permit a genuinely positive evaluation of progressive victories that are not reducible to class. This is perhaps clearest in the ambivalence that Mandel expresses over the apparent progressive victory in Morgentaler [1988]. On the one hand, he suggests that this case represents perhaps the only 'unqualified good result to come from the supreme court of Canada' (1989: 287) while on the other, he spends the next twenty pages condemning it. Because the substantive effects of the decision were split along class lines, the unqualified good result is ultimately portrayed as one that is, in the long run, bound to obstruct subsequent progressive political endeavours. Glasbeek and Mandel are rendered unable to see how partial victories can indeed constitute real victories. They fail to recognize that the politics of law yields decisions that, like all political outcomes, are fragile, partial, and contradictory (Gavigan $1990)$.

But whilst this class-centricism is clearly a point of theoretical failure, it also constitutes the point at which the authors make what is perhaps their most valuable contribution. Once we recognize the class-centricism in 
their position for what it is, Glasbeek and Mandel's work highlights the very crucial way in which formal legal gains do not necessarily have equally positive substantive spinoffs. 'Progressive' legal decisions can have very different effects, depending upon the class position of those affected (and, one should add, gender, race, ethnicity, linguistic group, etc.). In this sense, work such as Glasbeek and Mandel's is of capital importance in demystifying precisely the 'false' allure of formal rights. However, that allure is only potentially false, and progressive politics must, rather, endeavour to understand the conjunctural characteristics that might render formal rights devoid of substance rather than assuming they are, by definition, empty.

Economism also pervades their formulation of the necessary crises tendencies associated with the monopoly phase of capitalism. Even if we recognize that these are tendencies, as opposed to being what Glasbeek and Mandel present as pre-determined necessities, the authors still present events in the economy as necessarily determining the developmental trajectory of law. Thus, the charter is seen as 'the abstract form which legitimation must take in a capitalism no longer able to deliver the goods'(p.114; emphasis added). But the authors fail to give us any indication of what legitimation and accumulation crises in advanced capitalism have to do with abortion, language 
rights for Québecois, desegregation, etc. The point of connection for the authors seems to rest on the trite observation that most people have to work, and that the 'crisis of late capitalism - at least in advanced capitalist countries such as Canada - is fundamentally an economic one of severely declining living standards for workers' (p.113).

Both organized labour (Panitch \& Swartz 1987) and the welfare state (Myles 1987) in Canada have indeed been subject to serious attack by neo-conservative forces in recent years. But Glasbeek and Mandel's thesis of generally 'severely declining living standards for workers' fails to capture the complexity of the current conjuncture or provide it with a remotely accurate depiction of various regional, linguistic, racial and gender relations in canada. This, of course, is not meant to imply a rejection of class or its importance in analyses of this kind, but rather to suggest that other than an invocation of the name of Marx, Glasbeek and Mandel's analysis provides no basis for its reduction of social and political struggle to class struggle.

Finally, their economism leads to a blatant form of instrumentalism. The state is a capitalist state, staffed by capitalists who are there to serve the interests of capital. Because of their generally high incomes lawyers and judges are presented either as capitalists or as 
individuals whose interests are the same as capitalists. ${ }^{10}$ But the authors fail to recognize that congruence between the 'interests' of the state and the class location of its personnel on the one hand, and the interests and class location of the ruling class(es) on the other, 'is not the cause but the effect, and moreover a chance and contingent one, of this objective coincidence' (Poulantzas 1968: 245).

None of these points are intended to contest the notion that developments at the level of the economy do not have important, even crucial, effects at the levels of state and law. Indeed, I return to these themes in chapter four. Nonetheless, I wish to emphasize that there is no ineluctable logic of economic development and, more importantly, there is no economy-based pre-determined logic of development of other social-structural forms. The problems of essentialism and economism render Glasbeek and Mandel's approach to juridification questionable. The growth or expansion of the legal form is seen as just one manifestation of an inexorable series of legitimation and accumulation crises in advanced capitalism. But beyond merely asserting this as fact, the authors provide no theoretical or empirical substantiation for this claim.

${ }^{10}$ Income seems to be the determinant of class for Glasbeek and Mandel, an approach which seems wanting in the face of the professed 'marxism' of their analyses (pp.85-86, 96-97; C.f. Mandel 1989: 3, 9-14, 43, 246 and passim). 
With respect to methodological issues, Glasbeek and Mandel's work is plagued by ahistoricism. Whilst in some senses explicable in the case of their earlier article $(1984),{ }^{11}$ this ahistoricism has been retained in more recent incarnations of the legalization of politics thesis (Fudge 1988, 1989; Mandel 1985, 1989). Thus, the authors tend to extract both legal decisions and their results from their historical contexts. Not only does such an approach fail to give due weight to the politics that have brought specific issues into the courtroom, but incorrectly puts failed enforcement down as an inexorable failure of law and rights. ${ }^{12}$

The authors suggest that enforcement of progressive decisions is rendered unlikely because dominant social forces 'are more likely to be in favour of the overruled legislation than vice-versa (p.97). ${ }^{13}$ Such an approach

${ }^{11}$ In some respects this is a readily explicable weakness. What Glasbeek and Mandel are trying to do is to get some notion of what life after the charter might be like. Given that they were writing so close to the Charter's inception it was not only reasonable but also, prudent, that they look at the experiences of other countries in trying to access what sorts of impediments to progressive politics might be posed by the adoption of a constitutionally entrenched bill of rights.

${ }^{12}$ Thus, Brown v. Board of Education is extracted from years of black struggle. Similarly, Roe v. Wade comes to be seen more as a result of some inexorable logic of supreme court decisions rather than a critical moment in an ongoing struggle on the part of women to control their fertility.

${ }^{13} \mathrm{As}$ evidence here the authors cite the lethargy with which the positive formal gains of Brown $v$. Board of Education of Topeka were translated into substantive gains 
tends to underplay the very political nature of law and rights struggles, while failing to recognize that legal victories, like all political victories are at best, partial and fragile. Moreover, whilst it is true that formal rights might give rise to rights counter-claims from conservative social forces, any dismissal of such rights on this basis fails to recognize that claims and counter-claims are historically bounded, and that the relative success of either is more likely to be affected by the matrix of hegemonic social relations prevailing in a given conjuncture than they are to any essential conservative proclivities of the legal form generally, or of formal rights specifically.

It is this model that is used to inform the authors' analysis of the (legal) politics of abortion. I will now turn to a consideration of how this analytical framework affects their analyses of the abortion issue and then to a consideration of what their approach might offer the historical survey of abortion in canada as outlined in chapter one.

As noted above, Glasbeek and Mandel place a great deal of emphasis upon the fact that Roe led to a significant backlash from anti-choice forces. This is true. But the

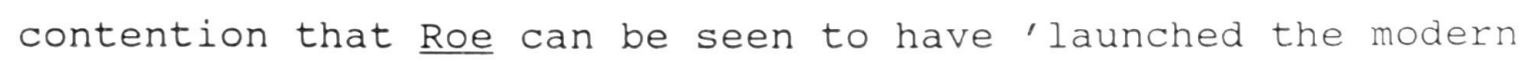

measured in terms of actual desegregation. They also suggest that 'the abortion victories in the American courts in the seventies did more for the "pro-life" movement than for the pro-choice movement' (p.97). 
US Right to Life movement' (Mandel 1989: 275) seems a very selective reading of history. ${ }^{14}$ As the material in chapter one attempted to show, the right-to-life campaign in the US rose congruently with the push for abortion rights. A multiplicity of events and actors came into play in the struggles around these issues. Whilst it would clearly be

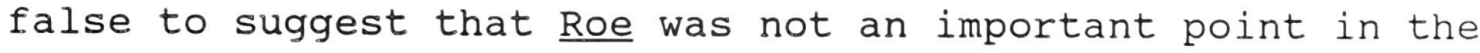
evolution of the debate, Luker's research suggests, quite unequivocally, that the original impetus for the growth of the anti-choice movement was inversely related to the legislated withdrawal of restrictive abortion legislation in many states prior to the USSC decision in Roe. The antiabortion movement had already gained a great deal of

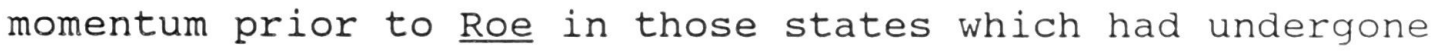
legislated withdrawal of restrictive abortion legislation $(1984: 127-137) \cdot 15$

${ }^{14}$ The authors make a general claim that formal rights claims are to be avoided because they give rise to rights counter-claims but often seem quite prepared, for the sake of propping up tenuous arguments, to ignore the historical contexts in which these events occurred. This aspect of their argument is so poorly developed that I will not address it further here. Rather, since carol smart's argument on this issue is somewhat better developed, I will pick up the discussion of rights claims and counter-claims in the following chapter in a critique of her position.

${ }^{15}$ The 1967 Beilenson Bill in California served as a crucial catalyst for anti-abortion forces. Indeed, it was the passage of this bill that really instigated the expansion of the 'right-to-life' movement in that state. Prior to this, anti-abortion forces in california had been dominated by Catholic male professionals (many of them physicians). After the bill's passage, grass-roots organization began to quickly spread (Luker 1984: 133-137). 
Clearly, Roe was a pivotal point in the evolution of the American debate, has been a lightning rod for the antichoice forces, and in many respects has served as a catalyst for subsequent organization. But these contentions must be carefully weighed against the historical fact that the right-to-life movement has arisen in the context of a broader series of social debates over fertility, foetal viability, and probably most importantly, broad-scale popular acceptance of discourses of familialism and the general rise of the new right (Petchesky 1990: 241-285 and passim). There is an obvious symbiosis between all of these events, but to attribute the degradation of any substantive potentialities Roe might have had on the decision itself is not only an unwarranted simplification of real history, but perhaps a strategically dangerous simplification.

Glasbeek and Mandel's very selective reading of the history of the abortion issue concentrates solely on the 'big' supreme court decisions. This keeps them from seeing the way the issue actually was played out in what they suggest are more democratic fora. As the californian experience in the years immediately following 1967 attests, political advances, regardless of whether they are achieved in the courtroom of the legislature, are likely to produce a formidable and tenacious response from opposing forces if hegemony has not been secured in the issue area. 
oddly, the authors, who purport to be centrally interested in issues of class and history, suggest that whether or not the anti-abortion backlash in the wake of Roe had any effect on the US supreme court's decision in Harris 'is neither here nor there'(p.108). What they suggest is important, is the fact that Harris resulted in a class(read: wealth-) based skewing of abortion services provision (pp.108-109). The absurdity of this position is that it ignores the history of struggle around these issues. The law, on the other hand, was precisely shot through with these struggles. Moreover, Glasbeek and Mandel fail to place Harris in its appropriate historical and political context: Harris was a legal decision that arose out of a broader set of political-economic circumstances in which the question of publicly funded health care is often portrayed as an ideological affront to the principles of free market.

In general terms, the conclusions these authors draw regarding the hollowness of abortion-related legal 'victories' in the Us must be rejected. But along with the foregoing reasons there is one more: Glasbeek and Mandel's analysis fails to recognize the fact that, in the wake of Roe, many women could now, without fear of criminal sanction, begin to exercise some modicum control over their reproductive capacities - no mean feat, and certainly not 
one to be taken lightly given the inherent legitimatory potential of supreme court decisions. ${ }^{16}$

Glasbeek and Mandel have little to offer an analysis of the abortion issue in Canada. Mandel's ambivalent attitude towards the outcome of Morgentaler [1988] is evidence to the confusion their position can inject into debates over law and its political utility. The inadequacy of their approach is perhaps most clearly highlighted when we consider simultaneously their approach to juridification and their treatment of the issue of abortion. Whilst they treat the Charter and US constitutional cases dealing with the issue of abortion as examples of the 'legalization of politics in advanced capitalism', the historical survey presented in part one suggests something quite different. Their dedication to a thesis which posits a trajectory of more law and more legal obfuscation of social relations of oppression totally ignores the fact that women's fertility has been regulated by law in Canada since 1810, and to suggest that 1810 to the present constitutes the era of 'advanced capitalism' in Canada seems a very limited periodization of history. Moreover, to suggest that Charter law is somehow

\footnotetext{
${ }^{16}$ I do not, for an instant, wish to idealize the
} radical potential of court decisions like Roe. Nor do I want to suggest that Roe fundamentally transformed the lives of all American women. What I will suggest, however, is that these decisions did indeed make a difference and opened up new terrain upon which women might be able to take up their struggles for reproductive freedom. I will return to these issues in detail in the final chapter. 
more political than criminal law is highly suspect. And this is not to mention administrative, tort, welfare state, contract, and other forms of legality and legal contestation.

Chapter one endeavoured to highlight just how crucial the organizational capacities of a budding medical community were in shaping the legal framework within which issues of reproduction would, for years, be fought out. But the medical domination of issues related to reproduction began to unravel, and the relevant laws entered a period of crisis and contradiction when developments in the field of reproductive technologies effectively rendered the defence of necessity a myth. The general instability engendered by this internal crisis was paralleled and intensified by external events in the forms of rising discourses of family planning and foetal viability, and perhaps most importantly, the congelation of two new actors on the political-legal stage - the pro-choice and pro-life movements.

Glasbeek and Mandel offer us no way of understanding this complexity. For them law seems to represent a sort of stasis of oppression, inseparable from dominant social interests. Thus, if we can only avoid taking recourse to law (or at least formal rights) we might be able to subvert its very foundations and the relations of oppression which the nature of the legal form mystifies. Agents are not absent in this conception, but their capacity to intervene 
at law in efforts to make their own history is rendered nil. Agents only exist outside law, and efforts to contest claims at law are pre-determined by law's essential rigidity.

Chapter one stressed the notion of 'identities' and the failure of law to reflect some identities whilst advancing others. This would seem to concur with Glasbeek and Mandel's position. But chapter one also stressed the confluence of numerous social forces and struggles that might converge in a given conjuncture to force a shift or rupture in the prevailing configuration of interests dominating any one issue area. This capacity for non-class forces to have a genuine impact on law is lost on Glasbeek and Mandel. They seem to feel that gains at law must not only be substantive, but complete and irreversible as well. clearly it is important that formal gains be translated into substantive gains. It is also important that progressive forces continue to struggle ensure that such gains are given and retain their substance. In a discussion of formal equality rights shelley Gavigan has suggested:

To observe, for example, the women have not achieved real equality despite the successful struggle for the vote does not [or should not] necessarily lead one to conclude that the concept of formal equality is only a mystification or a sham. As Juliet Mitchell has argued, attaining the vote was, at the very least, 'itself a certain progress, which can help make possible a further advance'.

$(1986: 285)$

Feminists and members of other social movements must be careful not to mistake the partial, incomplete and 
contradictory nature of legal and political victories with failure of their respective projects. In terms of legal 'victories', what is necessary is to translate formal progress into substantive gains. Clearly this cannot be done only within the realm of law, but it is highly unlikely to be achieved from without.

In a discussion of the role of the state Michèlle Barrett makes a comment on the relationship between women and the state which, I believe, is equally pertinent to the current discussion regarding the relationship between law and progressive struggles. Barrett suggests that

... the state is not a pre-given instrument of oppression, but is a site of struggle and to some extent at least responsive to concerted pressure. Although it would be just as ridiculous to claim that such pressure could of itself bring about women's liberation as to think that it might bring about socialism, to reject this level of struggle altogether is to lapse into the romance of anarchism.

$(1988: 246)$

The call to avoid the charter ignores the fact that, as a relational structure, law both shapes, and is shaped by, society. It is not impervious to struggle. To attempt to move struggle outside of law is to equally lapse into the romance of anarchism.

As Panitch and Swartz argue (correctly, in my view), 'Although the practical effect of constitutional phrases may not, of themselves, be great, inclusion of such rights at least furthers their legitimacy within the framework of political discourse, and thus may help ... in gaining 
support when it comes to struggles defending or extending such rights'(Panitch \& Swartz 1988: 102). Whilst progressives must remain vigilant to efforts that would dismantle the gains they have made, to attempt to move social struggle wholly outside the law, or even outside the contestation of formal rights, seems unrealistic.

\section{Summary}

Glasbeek and Mandel's work is one example of a common theme in many currents of social and political theory today, one which seeks to provide an understanding of a seemingly general tendency in western societies toward 'juridification', or an increase in the degree and scope of legal regulation of the social order. Their position suggests that such tendencies are inherently antithetical to the interests of progressive political forces. In contrast, I have argued here that much of their analysis is flawed by essentialism and economism. Their approach fails to allow for either an adequate conception of social struggle or the relational nature of law, and suffers from a general failure to provide any basis for understanding the role of the state and law in the regulation of social phenomena not readily reducible to economy and class.

In sum, three aspects of Glasbeek and Mandel's work deserve mention. First, their emphasis on class does serve to point up the important fact that legal decisions can 
often have highly differentiated impacts on social subjects, depending upon their class location. But the authors fail to offer insights into the way in which class is articulated with other forms of oppression. Moreover, the lacunae presented by their class reductionism cannot be corrected by merely adding gender, race, etc., to the list - the argument is still fundamentally flawed by its acceptance of the reduction of the legal to the commodity form. Second, whilst their analyses clearly suffer from a methodological ahistoricism, their peculiar brand of legal empiricism nonetheless does serve to highlight the historical fact that progressive politics often find law resistant to change, supportive of prevailing social relations, and sometimes even reactionary. Unfortunately, they give us no theoretical basis upon which we might better understand why this has historically been the case. Finally, their approach highlights the debilitating inadequacies arising out of theoretical reductionisms. 


\section{Chapter III}

\section{The Creeping Hegemony of the Legal order}

Another, and somewhat more sophisticated, approach to juridification tendencies comes from the work of carol

Smart. Smart has recently suggested that women eschew, whenever possible, recourse to law as a basis for the contestation of feminist challenges to the existing order. For Smart, law has, more often than not, failed to provide redress for women's oppression in the past, and has instead disqualified women's accounts of their lived experiences. Furthermore, law is coming to take on new social significance. She suggests that we find ourselves entering into a 'new era' $(\mathrm{p} .146)^{1}$ in which law, with its powers of regulation, discipline and surveillance, can insert itself into the most intimate spaces of our personal lives. Given past failures of feminist challenges at law, smart offers a warning for women 'to resist the move towards more law and the creeping hegemony of the legal order' (p.5).

As was case in the previous chapter, the conclusions in this chapter largely represent a rejection of the theoretical position under review. A critical assessment of Smart's work is important for a number of reasons:

- first, in advancing a position whose central premise is 'the creeping hegemony of the legal order' Smart's analysis, too, readily falls in with those lines of social and political critique

${ }^{1}$ All references in this chapter are to carol smart (1989) unless otherwise indicated. 
that posit what I have termed 'juridification theses';

- second, her theoretical framework purports to ground a political prescription (that women avoid the false appeal of law and its promises of formal, as opposed to substantive, progress in women's struggles for emancipation;

- third, where the previous chapter highlighted the limitations inherent in some marxist efforts to reduce essence of law to one arising out of economic relations, Smart's position highlights the limitations inherent in some recent strands of social theory which, whilst overtly rejecting 'grand theory', still reduce their criticisms of law to a core (androcentric) essence;

- fourth, in the course of her analyses smart highlights the fact that, historically, women have not generally been able to achieve profound leaps forward when their political strategies focused solely, or even primarily, on law. This historical reality serves to highlight, once again, the point made by Glasbeek and Mandel that law is often limited, or perhaps even a potentially regressive mechanism when progressives endeavour to employ it as a means to substantive ends; and,

- fifth, in taking us beyond the bounds of class and economy, smart injects two crucial points of reference for analyses of law - the role of law vis-à-vis the disciplines of Foucault's 'modern episteme' and, in turn, its place in the social shift toward disciplinarity;

- finally, Smart's position has some interesting things to say about the role of law insofar as women's struggles to gain control over their reproductive capacities are concerned.

The format of this chapter follows that of the previous chapter. The first part outlines Smart's general

theoretical argument whilst the second offers a critique of both theoretical and methodological aspects of her position. Finally, the third part examines her treatment of the abortion issue and attempts to glean whatever insights might be derived from this work insofar as the politics of abortion in Canada is concerned. 


\section{The Roots of Law's creeping Hegemony}

In developing her theoretical position smart draws heavily upon Foucault's conception of power and its sources in the disciplines of the 'modern episteme', the system of knowledges that have grown up around (scientific) professional discourses. Like Foucault, smart notes the importance of the rise to prominence of the 'psy' professions (psychology, psychiatry, psycho-analysis) and other medical and scientific discourses. These discourses have come to take on particular significance in contemporary society as they constitute relatively closed systems of knowledge; to challenge or contribute to their knowledge base one must be versed in the special techniques of the discipline in question. Thus, the disciplines are able to engage in what is largely self-regulation and to restrict membership on the bases of acceptance of established knowledge bases. Foucault's object of investigation is not 'the truth' per se but, rather, with the bases of different discourses' claims to truth. Through closure of access to both membership and knowledge, and through claims to scientificity, these discourses are able to disqualify other, competing discourses, the 'truth claims' of the latter being largely undermined by the 'scientific' methods of the former.

Smart carries much of this line of analysis over to an analysis of the power of law. In her recent book Feminism 
and the Power of Law (1989), she suggests that law is currently enjoying a creeping hegemony. In this formulation, the turn to law as the preeminent source of social regulation is seen as an endemic feature of technologically advanced societies. But in contrast to Foucault, who sees the disciplines displacing the loci of power of the ancien régime - namely the state and law Smart contends that law is not being displaced as a source of knowledge and truth. Instead, she argues that law 'has its own method, its own testing ground, its own specialized language and system of results. It may be a field of knowledge that has a lower status than those regarded as "real" sciences, none the less it sets itself apart from other discourses in the same way that science does'(p.9). Thus, Smart suggests an unequal symbiotic relationship between law and the disciplines in which law is able to attain new levels of social significance by virtue of its own method and its ability to draw on the expert knowledges of the disciplines with the ultimate effect of enhancing its own claims to legitimacy. In these terms the legal order is seen as enjoying a creeping hegemony in advanced societies.

In light of this growing hegemony smart warns women to be wary of law, and to attempt to de-centre it whenever possible. Feminism, she argues, is 'too easily "seduced" by law, and even where it is critical of law it too often attempts to use law pragmatically in the hope that new law 
or more law might be better than the old law'(p.160). These hopes, she asserts, are likely to be dashed for a number of related reasons.

First, she warns women of the juridogenic potential in law - that is, the very real possibility that a turn to law to achieve social remedies may well make matters worse (pp.12, 161-162).2 In particular, smart points to the juridogenic nature of rights claims - that is, the problem of rights claims making matters worse insofar as they tend to elicit counter-claims. Thus, when women claim a right to reproductive freedom, this opens space for others to make opposing counter-claims.

In addition, smart suggests that rights claims heighten the move toward greater surveillance (p.162). The unequal symbiosis between law and the disciplines of Foucault's 'modern episteme', in which law ultimately realizes hegemony, leads to entrenchment and legitimation of new technologies of surveillance, regulation and normalization - technologies informed by the disciplines but largely regulated and realized via the medium of law. For example, medicine and other social services are distributed on the basis of eligibility criteria which the recipient must meet if she is to lawfully access those services.

'Smart derives her concept 'juridogenic' from the medical term 'iatrogenic', the latter being the propensity for some medical treatments to actually worsen the condition of the subject. 
[R]ights can be claimed only if the claimant fits the category of persons to whom the rights have been conceded. Hence the state must have detailed knowledge of each individual... In order to claim rights the individual must fit into the specified categories; the rights are not basic rights but formal rights and conformity to specification is a prerequisite for exercising such rights.

The extension of rights has therefore been connected to the growth of the technology of the disciplinary society.

Thus heightened social regulation leads to heightened surveillance of the social body, and this type of scenario is to be avoided if and whenever possible.

Second, smart suggests that law is, at base, androcentric, and that a turn to law represents tacit acceptance of law's position in regulating society (pp.2025, 160-161 and passim). The problem here is clear: if 'law's language' and legal method and procedures 'are fundamentally anti-feminist or ... bear no relationship to the concerns of women's lives'(pp.161-162) then women must be wary of turning to law for social remedy as this in turn legitimates 'a mode of social regulation which is deeply antithetical to the myriad concerns and interests of women'(p.164).

Finally, Smart notes the power of law 'as a discourse which is able to refute and disregard alternative discourses and to claim a special place in the definition of events'(p.162). Thus, the androcentric standard at law has tended to disqualify feminist appeals to law. Further, it has rendered law quick to adopt the rights counter-claims of 
men who would challenge any inroads women have made in the advancement of their claims to equality. ${ }^{3}$

\section{The Politics of Abortion}

\section{and the Creeping Hegemony of the Legal order}

The foregoing provides the general theoretical backdrop for most of the analyses contained in Smart's book. But when she turns her attention to the legal regulation of women's reproductive capacities smart develops some important additions to this general approach to law (pp.146 ff.).

For Smart, the relationship between law and abortion is primarily one which has to do with rights claims. But, in her view, whilst rights claims may have constituted an important basis for the advancement of early (particularly first-wave) feminist political demands, she suggests 'that the rhetoric of rights has become exhausted, and may even be detrimental'(p.139) as a means whereby feminist political goals might be advanced.

Smart posits five crucial problems with using rights as a part of feminist strategy. First, rights claims tend to over-simplify complex social relations. For instance, the notion of a woman's right to choose readily obscures the fact that many women's socio-economic reality effectively

${ }^{3}$ of course women, too, might advance counter-claims. This is not, however, a point which smart seems interested in exploring. 
negates any real choice in the decision whether or not to carry a foetus to term. In such cases, rather, abortion becomes a must, a predicament in which many native women and women of colour find themselves (c.f. Petchesky 1990: passim). An example of this from the canadian case might include mention of the fact that whilst the popular rhetoric of a 'woman's right to choose' seems to have gained both currency in popular discourse and formal weight in the wake of Morgentaler [1988], this general rhetoric of a woman's right to choose has overshadowed the fact that that choice is seriously limited by virtue of the regional differences in the availability of abortion services.

Second, as noted above, smart feels that rights claims should be avoided because they tend to elicit competing rights claims and/or counter-claims. This is a crucial exemplar of Smart's conception of juridogenesis. Rights claims tend to give rise to counter-claims which in turn tend to be judged within a legal framework which is fundamentally androcentric in its orientation. One need not look far in the Canadian case to see crucial examples of just these sorts of events. The recent charter challenges instigated in Borowski V. Attorney General [1987], or in the dramatic injunction cases of Tremblay V. Daigle [1989] and Murphy V. Dodd [1990] are instances of just these sorts of problems. Of course, in all of these cases, the feminist side was 'victorious' to the extent that the claims made by 
opponents to a woman's right to choose were overturned. But, Smart is quick to point out that the resources expended in these sorts of struggles could be spent more constructively elsewhere, in ways that would not directly elicit rights counter-claims.

Third, whilst rights are articulated in such a way as to remedy social wrongs, action to remedy rights violations are 'always (in the UK at least) focused on the individual who must prove that her rights have been violated'(p.145). Smart's development of this notion of the 'rights and wrongs' of rights draws on the example of sex discrimination legislation and the way in which individual women must take a pro-active stance toward the law in order to force its terms. In this way such legislation is rendered devoid of substance for most women. A variant of this argument might be developed vis-à-vis the abortion issue. Such a predicament often faces women who are effectively denied abortion services because they live in a region in which such services are not provided. Individual women are left, in the wake of cases like Morgentaler, to struggle individually for equal access to abortion services.

Fourth, as was noted above, smart suggests that in order to claim a right in the age of the welfare state, one must prove that he/she fits the eligibility criteria. In turn, this heightens the trend toward greater surveillance and social discipline. 
Finally, although rights claims are generally popularly perceived as means to provide protection to the relatively weak, they can often be appropriated by the more powerful in society to actually thwart their originally intended impact. For our purposes, this notion is intimately tied up with that of the claims/counter-claims argument and will not be further developed here. ${ }^{4}$

With this critique of the efficacy of rights smart proposes the abandonment of rights strategies in women's pursuit of greater reproductive freedom. Armed with numerous examples of the past failures of formal rights she declares that:

...the language of rights carries with it a presumed lever on the state. This is a lever that has worked to a greater or lesser extent since the turn of the century. However, this lever may no longer operate as political conditions change. Since 1979 rights have been increasingly transformed into individual rights. That is to say that the state feels little or no obligation to ensure that the collectivity can enjoy rights. so rights claims have a different purchase as political and economic climates change.

${ }^{4}$ It is important to point out that smart does not reduce this position to the claims/counter-claims argument. Rather, she is concerned to point out how vague, general formal rights, which were initially implemented to help the 'weaker' in society oft-times wind up being appropriated by those more powerful as a means of enhancing their own power. of course this problem relates to the problem of rights counter-claims, but it goes further. Thus, arguments regarding the 'right to a family life', a principle originally formulated to deal with problems like forced mobility of labour, have now been turned around and are being used by unmarried fathers (more powerful) as claims against unmarried mothers (the weaker) for legally enforced access to their illegitimate children. 
From these considerations she suggests that '[s]uch considerations might lead us to consider whether victories in the field of rights claims are not rather hollow' (ibid.). Oddly then, whilst seemingly recognizing that the substantive content of rights will vary according to the conjuncture, she attempts to develop a general theory of the substantive hollowness of rights, in part by extrapolating from the British experience since 1979.

Smart does not merely attempt to expunge 'rights' talk from feminist strategy; rather, in the specific area of reproductive rights, she attempts to develop what she sees as a potential alternative to rights strategies. She suggests that inroads have been made in recent years through an eschewal of rights claims in the field of child custody law wherein rights claims have been displaced by the 'primary carer principle'. In this latter formulation, Smart claims, the concentration is not upon women's rights. Rather, decisions as to who should legitimately be given custody of children in family break-up are increasingly made on the basis of which parent has been the children's primary care giver. This, she claims, has undermined the potential for rights counter-claims from negligent fathers.

Smart suggests that a similar principle might inform feminist strategies vis-à-vis the abortion issue. She argues:

that we need to reconceptualize pregnancy as a period when women are actually actively nurturing 
the foetus. This challenges the ideas that the mother and the foetus are simply separate entities which the rights argument does so much to sustain. If pregnancy is seen as a period of nurturing then the mother's active participation and willingness to provide care becomes central to any decisions which may have to be taken. As primary nurturers, women's material conditions would provide the basis for her (sic) being given priority in decision making. This avoids the possibility that decisions would be taken over women's heads to force them to go through with unwanted pregnancies.

Thus, she points up the importance for women to combat the popular conception of woman and foetus as two separate persons, each with potentially competing rights. The alternative, she suggests, would help get around the individuating effect of rights language - language which forces this false separation.

\section{The Creeping Hegemony of the Legal order: An Assessment}

With this framework, Smart sets out to demystify the allure of law. Taking on a number of issue areas - rape, child abuse, pornography, child custody, and abortion - she systematically demolishes the myth of law as a panacea for resolving women's social subordination. As such, smart's overall picture of law provides an excellent synthesis of much of contemporary feminism's critique of law. There are, however, serious problems with the theoretical and methodological underpinnings of her position. First, the underlying premise of her book - the creeping hegemony thesis - injects an unnecessary determinism into her 
argument. Second, and relatedly, the growth of law is seen as a function of its symbiosis with the disciplines - an unequal symbiosis in which law generally tends to gain greater disciplinary powers. This presents a reified notion of law and the disciplines insofar as they tend to be seen as separated from their social conditions of existence. Third, in an effort to adduce historical evidence to support her general thesis, smart tends to lapse into a methodological ahistoricism. Finally, expunging the determinism in her position calls for a reconsideration of her position on rights.

The determinism in her position stems from her perception of law as necessarily becoming increasingly omnipresent in society. Law shares in this trajectory with the disciplines of the modern episteme in a relation of symbiosis. In terms of legitimation and the capacity to discipline, this symbiosis becomes mutually legitimating: law enhances the power of the other disciplines by legitimating their knowledge and truth claims, which in turn enhances law's own basis of legitimation. Thus advances the disciplinary society with all its powers of surveillance and control. This seemingly forward march to juridical/legislative omnipresence is to be resisted by women because law is juridogenic, androcentric and is prone to disqualify alternative discourses, particularly those based on women's experience. 
Smart goes beyond merely highlighting the empirical fact that feminist strategies have often been limited or wholly unsuccessful when law was one of the strategic mechanisms chosen to advance progressive change. Instead, her warning about law as a strategic choice is theoretically grounded in the notion that law is a central component of the inevitable shift into a disciplinary society. Law, particularly more law, is portrayed as an essential component of a pre-determined shift into disciplinarity. It is in this sense that smart's work follows a broader sociological and political literature which highlights juridification tendencies in contemporary modern societies. Whilst warnings of the negative potentialities inherent in the rise of the disciplines and some forms of social regulation through law are both prudent and necessary, the shape that individual social formations are likely to take in this 'new era' cannot be pre-determined, nor are they necessarily likely to be negative. Rather, the specific shape that they will take will be determined by internal social struggle mediated by external forces (i.e. the international political economy and women's condition in other countries). For the most part, however, Smart's work seems premised on the notion that law's regulatory scope is expanding, and that that expansion is undesirable, in part because law, as a crucial element in the march into disciplinarity, is inherently bad news. 
It is an uncritical appropriation of one aspect of Foucauldian analysis that appears to lead smart into this trap. Foucault's primary object of investigation was social power. But in opposition to traditional conceptions of power which conceive of power in terms of a top $\rightarrow$ down schema (i.e. state power vs. powerless individuals), Foucault was interested in examining the micro-physics of power, or power 'in those points where it becomes capillary' (Foucault 1980: 96). For Foucault, power is not only repressive, censorious and negative, but is, productive, normalizing and positive as well (Jessop 1990: 226). Unfortunately, these positive aspects of power seem to get lost in Foucault's methodological focus on the disciplinary effects of the discourses of the disciplines. The 'positive' aspects of power are clearly asserted but seldom explored. The bleak pictures of asylum and prison life and their attendant modalities of normalization leave the reader wondering just what Foucault means by 'positive' power.

Smart, whilst disputing Foucault's dismissal of the effectivity of law does, however, adopt his notion of a seemingly linear march into disciplinarity. Smart is thus concerned to highlight law's potential to insert itself into the most intimate spaces of our lived relations, and then to record, transmit, evaluate, etc., the outcomes of its surveillances. But, smart seems to accept Foucault's methodological focus on the negative side of power as a 
theoretical truism. This blocks any recognition on her part of the fact that the techniques of power, the extent of social surveillance and the limits of its intrusions, are issues which lie at the very heart of political struggle. But perhaps most importantly, these issues will not be resolved by eschewing recourse to the disciplines (including law) but rather through the transcendence of their oppressive potentialities - i.e. via both internal and external struggle and critique.

Smart allows this necessarily negative conception of law to guide her argument. In so doing, any flavour of historical variations in law's role in society are lost. Law becomes merely one part of a 'musical score conducted by a world maestro' (Lipietz 1987: 9). But it is an important part - one that disciplines society, and necessarily disqualifies women's experiences. It is in this sense that Smart's analysis is determinist. In turn, this determinism constructs the specifics of her argument; the negative potentialities of law take the fore, while the positive are only reluctantly ceded. Positive gains that might be had through legal strategies are thus presented as increasingly limited in this stream of analysis.

In Canada some have characterized legal and political events since the advent of the charter as possible supporting evidence of Smart's 'creeping hegemony of law' thesis (Gavigan 1990: 9-14). With respect to the legal 
regulation of women's fertility, this seems a tenuous position at best. As the two preceding chapters have attempted to stress, women's reproductive capacities have long been the object of legal regulation and are not a recent manifestation of broader juridification tendencies in modern societies. This is not to suggest that the charter has not rendered justiciable many hitherto non-justiciable claims. But, if the abortion case is any indicator, what is needed, and what smart fails to provide, is a more complete understanding of the different types of law - i.e. criminal, charter, welfare state - used to regulate these issues, and what each of these types might imply for women's struggles. Thus a politics guided by a thesis of juridification must distinguish between an actual expansion of law into social relations hitherto unregulated by law, and a displacement in legal regulation of one legal form in favour of another. The legal regulation of canadian women's fertility would seem to be an example of the latter, a displacement from criminal prohibition to the terrain of contestation over formal rights.

Many of Smart's warnings about the practical limitations of legal strategies aimed at social reform are echoed in numerous places in canadian feminist and socialist legal scholarship. ${ }^{5}$ But Smart's warnings, based as they

${ }^{5}$ See for instance: Fudge (1987), (1989); Gavigan (1986), (1987), (1989); Glasbeek \& Mandel (1984); Mandel (1985), (1989); Gotell (1990). 
are on the very real fact that women's struggles at law can, and often do, fail, must be extricated from notions of juridification. The turn to law since the charter might be better conceived as a series of strategic political responses to a specific institutional-legal form which opened up new discursive space for the contestation of political advantage. In this respect, the question may not be whether (as Smart suggests) we can any longer afford to pursue legal strategies, but rather, whether we can afford not to. In terms of the abortion issue in canada, a failure on the part of women to pursue legal strategies at this stage could be disastrous.

We must, however, be careful not to suggest this is an exceptional case necessitated by a mistaken feminist engagement with law in the formulation of the charter. Whilst that engagement has surely given rise to new strategic problems for feminism, it is not at all clear that women's position would not be severely strategically weakened had those engagements leading to the charter's ultimate provisions not been undertaken. In other words, the issue should not be framed in terms of whether women were correct to engage the debates that ultimately resulted in the charter. Rather, what are needed are analyses of the strategic implications the charter's introduction might hold 
for women's struggles in the future. ${ }^{6}$ Thus, the relevant questions turn on the issues of whether or not defensive or offensive (i.e. pro-active) litigious or legislative reform strategies should be adopted in a specific case. What Smart's work does add to this formulation is a recognition of the important role that women's everyday struggles against oppression will play in the compromises that will be achieved in the future. But whilst smart is correct to argue that the allure of law as the sole avenue of struggle must be resisted, she fails to recognize that as an important component of political strategy it cannot be ignored.

The symbiotic relationship smart posits between the disciplines and law is also problematic: it excludes any adequate conception of how struggle may shape the configuration this relationship will take. Where law is seen to be devoid of autonomy for Glasbeek and Mandel, for Smart it exists in a relationship of relative autonomy from the other disciplines, and ultimately autonomous from everything else. Law becomes separated from society, the very basis of its existence. It is in this sense that Smart's model comes to adopt a reified conception of law.

${ }^{6} \mathrm{~A}$ similar line of argument is raised by Panitch and Swartz in response to Glasbeek and Mandel's approach to the charter and its strategic importance for workers (Panitch \& Swartz 1988: 102-103). 
But not only is law portrayed as autonomous from society generally, but any connection law has with the state is seriously down-played. Apparently following Foucault once more, smart develops a thesis of the symbiosis between the disciplines and law, at the expense of a conception of the state. For smart, the state is a concept that is both 'analytically vacuous and anachronistic' (Gavigan 1990: 12). For her, '... a concept like the state is so imprecise and misleadingly implies a monolithic unity of interests and regimes'(p.99). But this eschewal of the state results in two critical inadequacies in her formulation. First, any appreciation of the way in which social struggle is articulated and condensed in and through the institutions of the state is lost on smart. Second, and perhaps most importantly, is the failure in this sort of formulation to acknowledge the special role and place law has as a result of its articulation, not with 'the disciplines', but with the institutions of the modern state, both repressive and administrative.

One particularly important source of many of the problems outlined above is Smart's tendency to lapse into a form of methodological ahistoricism. For instance, on the one hand she overtly recognizes that 'rights claims have a different purchase as political and economic climates change'(p.152). On the other hand she is willing to draw on the experience of British women since 1979 as a basis to 
establish the generalization that victories in the area of rights claims are hollow (ibid.).

If smart's point is to underline that rights gained through struggle are not irreversible, then the point is well taken. I believe, however, that smart's analysis is fundamentally tainted by her creeping hegemony thesis and its concomitant assumption of a fairly progressive degradation of hard-won past struggles, the gains of which are lost to 'the disciplines', including law. Whilst recognizing the valuable insights that can and should be drawn from a more complete recognition of the role and power of law in the reproduction of women's oppression, what must be highlighted is that state law is fundamentally political, bounded historically by the social relations obtaining in a given national instance.

Moreover, this problem of ahistoricism is compounded by a tendency to treat law as law in general - as unitary. overtly, smart rejects this perception of unity, mindful of the contradictory and multifarious nature of law (p.4). This overt recognition seems, however, lost on the subsequent analyses. Rather, smart's presentation tends to treat adjudicated, legislated, and constitutional law as 'law in general' _ a problem which glosses over the very important strategic considerations which must necessarily inform the choice of one or another of these forms in a given conjuncture. Ultimately, the notion of law as 
'something out there', separate from the social conditions of its existence, informs the whole of the subsequent text, largely washing over the very political nature of law, its organic relation to the social, and its existence as an incomplete condensate of social forces.

Whilst smart's analyses do provide insights into some of the negative, repressive aspects of law, they largely foreclose any consideration of its potential as a mechanism for the advancement of social change. For instance, Smart's analysis does help us to better understand some aspects of the relationship between law and medicine. Until 1988, doctors had held a monopoly over the provision of abortion services in canada. In many respects it seems reasonable to suggest that the medical community gained greater social legitimacy and power through its legally sanctioned capacity to monopolize both the provision of this and other health services, and the knowledge that came along with that monopoly. In addition, it might be reasonable to suggest that, if successful in shaping the attitudes and behaviour of the social body, law can gain greater legitimacy and power.

But, the historical survey in chapter one would suggest that these proposed relations greatly oversimplify complex social and political struggles. First, they fail to provide adequate conceptual space for understanding the confluence of political forces that brought the medical community their 
monopoly in the first place. Attributing that monopoly to a relatively linear development of uneven symbiosis between law and the disciplines glosses over the fact that when abortions not performed by doctors were first criminalized, few actors - even a budding feminist movement - had the organizational capacities or moral/ethical inclinations to oppose the call for control of health care by the medical 'regulars'. Indeed, some of the most powerful voices of the early feminist movement were not only opposed to abortion but actually aligned themselves with the broader eugenics movement, whose ideological import was a crucial component of the new hegemony of medical regulars (Backhouse 1983: 73 ff.; Rothman 1989: 116; Petchesky 1990: 89-95).

Furthermore, as proposed by smart, the symbiosis between law and 'the disciplines' offers little room for explaining why and how the medical community's hegemony in the issue of abortion has come into crisis in recent years. That hegemony could be reasserted in the years to come in similar or different ways. Thus, we could see a reassertion of legislation which leaves formal control of the abortion decision in the hands of doctors or a partial return of medical decision making in the issue based on the stage of gestation. Conversely, we could conceive of alternative scenarios in which abortion were to be outlawed under all circumstances or, where abortions could be performed at the 
request of women at any stage of pregnancy. The compromises $^{7}$ arrived at in the future are as likely to depend on the social forces that come into conflict over competing perceptions of the moral, ethical and socioeconomic values at stake in the abortion debate as they are to depend on the exclusionary knowledges of the medical and legal communities.

Finally, Smart's critique of the strategic propriety of adopting rights discourse as a political tool is worthy of detailed consideration here as it lies at the centre of her discussion of abortion. To briefly recap smart's position on rights, she posits five problems with using rights as a part of feminist strategy. First, rights claims tend to over-simplify complex social relations, masking the underlying social inequalities that render formal legal rights gains relatively empty. Second, rights claims exist in the context of, or can give rise to, competing rights claims which, if successful, can undermine the substantive worth of past formal rights gains. Third, rather than remedying social wrongs, action to remedy rights violations are often focused on the individual who must prove that her rights have been violated. Fourth, whilst popularly perceived as means to provide protection to the weak, rights can often be appropriated by the more powerful, directly

'I use the plural 'compromises' here as it seems unlikely that for the foreseeable future this issue will be settled in anything resembling 'final' fashion. 
undermining their originally intended purposes. Finally, (and particularly in the case of welfare claims on the state), rights-claims often include eligibility criteria which the individual must provide evidence that she meets, in turn heightening the potential for repressive surveillance.

As I have stressed above, all of these considerations are strategically important for those who seek formal redress of structural social inequalities. The warning that law has juridogenic potentialities is a point well taken, as is the criticism that law tends to share or reflect a broader societal androcentricism. It is important to point out, however, that these are not essential aspects of law. Law is not prone by some pre-given essence to make things worse or to be necessarily guided by some masculine imperative to the inevitable detriment of women. Such contentions belittle the strides that have been made over the years by progressive social forces through political struggle aimed at overcoming oppression, and should be rejected as essentialist.

None of these points underlying smart's critique of rights, individually or in combination, constitute valid reason for the abandonment of rights discourse. What is needed, rather, is a closer consideration of the social relations obtaining both when such rights claims gain formal status in law, and at the time that such claims are 
contested subsequent to their formal adoption. Rights claims are likely to have greater substantive purchase if the ideas enshrined in those formal rights have managed to become instilled in people's 'common sense' perceptions of the way things ought to be: in other words, when those rights have managed to become articulated as a part of the hegemonic political discourse.

It is highly questionable as to whether or not smart has in any way displaced rights discourses with her 'primary care-giver' alternative. The interests of the 'primary nurturer' 'are not self-legitimating. If that were the case such interests would not be politically controversial.... The deployment of the discourse of rights has a special and distinctive role in the historical process of the legitimation of social interests'(Hunt 1990: 26). It is difficult to see how the claims of the 'primary nurturer' will be capable of being advanced and sustained without recourse to a mechanism such as rights-claims to provide them with the requisite popular purchase. In short, it seems that smart has merely replaced a woman's right to choose with the primary nurturer's right to decide to continue or terminate nurturance. Rather than advancing an alternative to rights, smart has merely advanced an evidential device for the recognition of a right. 8 Thus, whilst her position may provide some insights into how the

\footnotetext{
${ }^{8}$ I am indebted to Alan Hunt for this formulation.
} 
issue should be articulated within a broader feminist politics it fails altogether to escape the discourse of rights. In turn, her eschewal of law on the basis of 'the hollowness of rights' is rendered highly suspect.

It is of course vital that women attempt to displace those discourses which tend to humanize the foetus and which separate it from the body sustaining it. But the historical analyses in chapter one would suggest that the humanization and personification of the foetus has been fuelled at least as much by a general rightward shift in political discourse and by advances in reproductive technologies as they are based on a reaction to women's rights claims at law. It is most unlikely that abortion would have been de-criminalized if women had never introduced the 'right' to choose as a key political demand. It seems even less likely that if women were to abandon the struggle for the right to choose, that others would drop their arguments in favour of the rights of the foetus. Whilst it may be important to re-articulate the right to abortion as an element of a broader feminist politics, this does not presuppose getting rid of rights claims.

Rosalind Petchesky has formulated a much more useful conception of the importance of rights discourse to women's struggles, particularly insofar as they effect women's decisions whether or not to carry pregnancies to term. 
individualism that rhetoric has generated in western liberal, legal, and feminist traditions from the collective, communitarian dimension of rights claims in diverse contexts of political action. In such contexts, rights become one critical discourse through which collective identities are defined, publicly announced, and tentatively achieved in particular historical moments. They are thus part of the narrative through which collectivities (women, blacks, gays and lesbians) become constituted as public selves and are empowered to engage in political action. In short, we could not abolish "rights talk" without abolishing politics altogether.

(1990: 395; emphasis added)

Thus, in Petchesky's formulation, rights claims constitute a critical discursive strategy in the pursuit of social change.

What is particularly insightful about Petchesky's formulation is her call for a transcendence of abstract individualism of liberal rights discourse in favour of a 'social rights discourse'. This is crucial as it places the 'right to choose' in a context which renders choice 'real'. To do this requires an articulation of the right to choose within a broader counter-hegemonic project aimed at the alleviation of the socio-economic inequities that have for so long and so often rendered black, immigrant, native, poor, and working women's right to choose an empty one. As she suggests:

[I]n order for the "right to control our own bodies" or the "right to choose" to become truly "a collective assertion of right in the demand for a new ordering of social possibility" it must address itself to the needs of all women. The social conditions of bodily integrity have to 
become universally available, and that set of transformed conditions has to become inherent in how we define reproductive (or any) rights.

In contrast to smart, who suggests that rights discourses are increasingly becoming a major contributor to the perpetuation of women's subordination, Petchesky looks to the broader political climate within which rights discourses have been advanced: i.e. the particular sort of abstract liberal individualism which has dominated the rhetoric of the New Right, and has served as the basis for such legal decisions as that rendered in Harris V. McRae. Petchesky's insights point to the absolutely crucial need to articulate calls for reproductive autonomy with a broader counter-hegemonic discursive strategy - one which recognizes, for instance, that for poor women, the right to choose is no choice at all when you haven't the economic wherewithal to raise a child.

This type of rearticulation of reproductive rights discourse has important implications for the Canadian case. As the historical overview presented in chapter one would suggest, the hegemonic liberal discourse within the canadian women's movement has not only thwarted the insertion of women's choice as a central political issue on the agenda of the Canadian women's movement, but it raises the question as to how much that dominant discourse of liberalism has served to undermine the types of social reform that might effectively render all women's choices real. 
The foregoing leads to a slightly more optimistic view of rights than smart is willing to cede. In contrast to Smart's position, I would suggest that rights victories, like all political victories, are necessarily temporally and spatially contingent, and are often fragile, contradictory and incomplete. Furthermore, rights claims as yet unrealized in legal form might better be seen as hegemonic potentialities, the viability of which are dependent upon the successes of practical and theoretical struggle (Bartholomew \& Hunt 1990).

The rise of the New Right in the last decade and a half signifies not the hollowness of rights victories but, rather, that rights victories at law cannot be expected to carry the whole weight of social struggle. Rights claims must, rather, be articulated within a broader political discourse. It is the popular cogency, the common sense appeal of rights discourses that render them viable mechanisms for social change. In this sense it is not surprising that, when emanating from a predominantly liberal hegemonic discourse, social rights - including aspects of the right of reproductive freedom - have come under fire in recent years.

The final word in this chapter should perhaps go to Gramsci whose thoughts on the construction of a counterhegemonic project are instructive here. For Gramsci, 'it is not a question of introducing from scratch a scientific form 
of thought into everyone's individual life, but of renovating and making "critical" an already existing activity'(Gramsci 1971: 330-331). As in the case of 'rights' discourses in general, it is not a question of necessarily purging radical politics of the elements 'which are constitutive of the prevailing hegemony' (Hunt 1990: 9), but rather, of unveiling their occlusions through practical and theoretical struggle. An effort to extend a conception of rights to include, centrally, social rights, is precisely what is contemplated by this notion. Thus, liberal conceptions of privacy might be rearticulated within a broader discourse of social rights, it may well form the theoretical basis for a politics which rejects the types of surveillance and discipline which are of such central concern to authors like smart and Foucault.

Such a critique might, for instance, extend feminist and socialist scholarship which aims at overcoming the ideological effects of the public/private distinction which pervades so much of liberal legal ideology and which has had the effect of situating 'family' issues beyond the scope of state intervention. 9 But rather than rejecting the

${ }^{9}$ There is a broad literature on the nature of the public/ private distinction. Within feminist scholarship this duality is seen as a particularly important point of focus, as liberal conceptions of ideology are often interpreted as placing social relations of intimacy beyond the purview of the state, and in turn laying the basis for the perpetuation of such relations. See for instance: Mackinnon (1989: 184-194); Fudge (1987); and Barrett (1988). 
importance of privacy, such a radical critique could form the basis for a more coherent politics of social rights. Such an alternative conception of privacy is what Wendy Kaminer has in mind when she suggests, 'it is an ideological as well as a political mistake for feminists to dismiss privacy rights as mere property rights or instruments of patriarchy: They include rights of self-determination, and without self-determination, what use is equality?' (Kaminer 1990: 181). Whilst these suggestions are tentative, they do, I believe, hold out promise in terms of how we conceive of relations between state, society, law, and social regulation.

Law and legal struggle will surely constitute an important locus of struggle in the constitution of future compromises. of particular importance here is a feminist recognition, and sustained critique, of the ideological role of law. It is in this regard that smart's work is perhaps most important, highlighting the impact law has on defining the parameters of political contestation. But what is lacking in Smart's formulation is a clear recognition that those parameters are bounded historically, and exist as partial condensations of social struggle. The occlusion of women's experiences at law is not defined by any immutable logic of law, but rather, stems from the social conditions of law's very existence: social relations. 
A critical theory of law must aim at ferreting out those aspects of law that tend to occlude relations of oppression. Here smart offers some interesting points of departure. But a critical theory of law must also endeavour to understand the role, nature and radical potentialities of law. This includes the capacity to explain progressive legal victories as other than a smoke screen to dull the senses of the oppressed. Here smart's approach, like that of Glasbeek and Mandel, fails us.

\section{summary}

A radical critique of legal theory, concepts and method are crucial to the construction of a counter-hegemonic project. Whilst smart makes some moves in this direction, this chapter has argued that she fails to develop a tenable theoretical base that might sustain her sweeping prescription for a general eschewal of law. Whilst the call for women to avoid engaging law whenever possible may at times be a wise strategic recommendation, the choice of whether or not to engage in legal struggle must be informed by the specificity of the conjuncture. Thus, the role of law in the evolution of the abortion issue can be better understood in light of the broader social context within which the struggles surrounding the issue have been carried on. Unfortunately, Smart's position tends to ignore the historical specificity of law, mistaking law's rigidity and 
its tendency to reflect aspects of hegemonic social discourses (particularly those of androcentricism) for essential attributes of law. Ultimately, her theoretical argument is unable to sustain her political prescription. Whilst smart is correct to stress the political limitations of legal strategies, the same can be said of any political strategy. It is crucial to recognize the formal impediments to any political strategy, and to develop such strategies in full recognition of those limitations and with a view toward their ultimate removal. One important contributor to developing such strategies is a conception of law which avoids the sorts of determinisms and reductionism that pervade the approaches reviewed in this chapter and the last. Chapter four offers a tentative outline of an alternative approach to law which endeavours to avoid the lacunae presented by the accounts of law offered by smart and by Glasbeek and Mandel. 


\section{Chapter IV}

\section{Toward a Non-Reductionist Account of Law}

So far this paper has chronicled the development of the legal regulation of women's fertility in Canada and has made an effort to situate this development within the context of some recent contributions to theorizing the relationship between law and society. Each of the two approaches outlined above bear certain merits. Neither has, however, provided adequate space for understanding law as a relatively autonomous element of social life. Nor have they provided a means whereby we might better understand the apparent juridification of the social. In turn, they fail to acknowledge that formal legal change need not necessarily be substantively empty.

In this chapter I move toward a conception of law which highlights its organic relation with the social, and the role that law plays in demarcating the boundaries of legitimate political contestation. Law is not merely a functional mechanism that ensures the expanded reproduction of capital; nor is it reducible to status as a mechanism of discipline symbiotically related to other such mechanisms in a march toward a future of surveillance and discipline. These points clearly do have some basis in fact. As elements in the broader social environment within which law develops, capital and the (other) discourses of discipline necessarily partially constitute the conditions of law's 
very existence. But - and this is the central problem with the perspectives reviewed in chapters two and three - these do not exhaust the range of actual or potential conditions of law's existence in the societies of western modernity.

One of the central themes that emerges out of the approaches to law reviewed in chapters two and three is that law is expanding, and is growing in its scope and power. 1 Each of these perspectives advanced its own reasons for opposing, what I have called here, processes of juridification, and each has drawn its own connections between the growth of law and the legal regulation of women's fertility. In each case, abortion rights and the legal regulation of women's fertility have formed a crucial empirical referent, and are deployed as examples of why law is to be avoided by progressive forces as a mechanism whereby progressive political objectives might be realized. But if, as I have argued above, these perspectives on law are theoretically flawed, then what can we say about what otherwise seems to be a genuine growth of law in modern societies? If juridification represents a real force in modern society, how should progressives understand this phenomenon theoretically, and how should such an understanding affect political practice?

\footnotetext{
${ }^{1}$ Not all approaches to juridification contemplate a necessary corollary increase in law's power. Some - for instance, Habermas (1987) — seem to suggest, rather, that legal expansion actually weakens law and ultimately undermines legal effectiveness.
} 
In this chapter I endeavour to provide a nonreductionist approach to some of the issues raised by those authors reviewed earlier. Having rejected the notion that law is necessarily becoming more pervasive because of its relation to either the economy or disciplinary social discourses, we are in want of a reconsideration of juridification theses. Drawing on recent insights of German systems theory, this chapter attempts to better situate theoretically the contention that law is expanding. This same systems theory provides the basis for insights regarding the autonomy of law as well.

But considering the insights from systems theory in the light of the historical review in chapter one also helps us to understand the limits of this theoretical approach. Most particularly, the structuralism of systems theory offers little basis for understanding strategic combinations of systems, and avoids the issue of agency altogether. A further conceptualization highlighting the strategic relations between sub-systems and between systems and agents is needed. This chapter attempts to develop such a conceptualization through a consideration of law's role as an interpellative structure, crucial to the transpositioning of subjectivities and their inclusion/ exclusion from the universe of political discourse.

Ultimately, this chapter endeavours to re-insert agency and strategy into a conception of the expansion of law in an 
effort to understand why a potentially expanding, functionally complex legal order might not necessarily bear negative implications for progressive social forces eager to apply law as a tool in struggle. A more adequate theorization of the growth of law, one that recognizes the way in which law is a condensate of past struggle, will help us better understand the limitations of legal strategies and, hopefully, their potentialities.

\section{Autopoiesis and the Autonomy of Law}

One of the chief lacunae of the theoretical approaches reviewed above is their failure to recognize the bases of legal autonomy. For Glasbeek and Mandel law has virtually no autonomy, whilst for smart its autonomy is articulated with that of the other disciplines. An interesting approach to formulating theoretical explanations to both the growth of law and the nature and bases of law's autonomy arises out of recent contributions to systems theory. Authors such as Habermas (1987), Luhmann (1985, 1987, 1988), Teubner (1984, 1987, 1988), Handler (1988) and Reich (1988) have all contributed substantially to these debates. For these authors too, law has grown, expanding its scope into regions hitherto unregulated by law, and they concur that such juridification tendencies may lead to pathological or anomic social tendencies. 
These authors generally examine social development in terms of the evolution of social sub-systems and the growth of system complexity. In these terms, a large part of the apparent expansion of modern law has taken place as a corollary of the expansion of national and international capitalist relations. Moreover, this approach invites a consideration of the role and development of communicative systems such as the disciplines, and provides a unique way of considering the apparent closure of disciplinary knowledges from general social access.

Luhmann provides a good starting point for an examination of the growth of law. For Luhmann (1985) the growth of law is directly related to an evolutionary tendency toward greater social complexity. Whilst law per se has a lengthy history, ${ }^{2}$ it is with the rise of modernity that positive law comes to take hold and become the primary basis of normative regulation in society. Where law once derived much of its legitimation from traditional and/or charismatic sources, heightened social complexity forces the abandonment of these as the primary legitimatory sources of normative regulatory processes. These sources of legitimation fail to provide the flexibility that would

'While Luhmann's account of law in archaic societies is at best partial (1988: passim.; for a critique see Hunt 1986: 193), it is nonetheless refreshing insofar as it does actually acknowledge forms of law in these earlier societies not readily reducible to either the commodity form or strictly related to Foucauldian notions of pre-modern sovereignty. 
permit them to cope with the high degree of social complexity attending modern social systems. As law becomes increasingly complex and alterable by decision, its basis of social legitimacy comes to shift more to internal standards of procedural and logical self-reference and less on extrasystemic legitimatory sources (deism, charisma, sovereignty, etc.). Law becomes increasingly normatively closed and reflexive whilst maintaining cognitive openness: it reaches autopoiesis. Law is, for Luhmann, one among many social sub-systems (e.g. law, economy, politics, the welfare state) which have similarly developed along functional lines in modern societies.

Luhmann's development of the concept of social autopoiesis ${ }^{3}$ constitutes a major point of connection between his project and those of a number of other authors interested in better understanding the autonomy, and limits to growth of, law (c.f. Teubner 1984, 1987, 1988; Handler 1988; Nelken 1988; Jessop 1987, 1990). Autopoiesis:

is a property of a certain type of system and can be defined ... as a condition of radical autonomy. It emerges when the system in question defines its own boundaries relative to its environment, develops its own unifying operational code, implements its own programmes, reproduces its own elements in a closed circuit, obeys its own laws

${ }^{3}$ Luhmann has pioneered the application of the concept of autopoiesis to social systems. The concept, however, originates in the biological and cybernetic systems analyses of Maturana, Zeleny and Varela (Jessop 1987: 35-45). 
of motion. When a system achieves 'autopoietic take-off', its operations can no longer be controlled from outside. ${ }^{4}$

(Jessop 1990: 320 )

Once a social system has experienced autopoietic take-off, the operative unity of an autopoietic system is produced and delimited through the operation of a system's 'elements'. In the case of the legal system, Luhmann identifies these elements as the body of 'legally relevant facts and decisions' (Luhmann 1985: 281-282).

Thus, autopoieticism sets itself up immediately as an approach to understanding the underlying bases of the autonomy, autonomization and self-referentiality of modern social systems. It is this reflexivity that places limits upon the range of considerations that the law or other autopoietic systems can meaningfully take on. This internal structure of law is likely to further limit the very range of broader social issues which are deemed to be 'legally relevant'. Thus, autopoietic closure acts as a structural filter partially determining the range of issues and actors that can be reasonably viewed as 'legal'.

Autopoietic systems experience events in their environments as 'perturbations'. Environmental

\footnotetext{
'The notion of autopoietic 'take-off' (Jessop's term) is variably referred to in the literature as the 'constitution of a hypercycle' in the reflexivity of social systems (Teubner 1987: 218) and as the point at which a social sub-system develops the scope of activity for the auto-genesis of its own elements (Teubner 1987: 223; Jessop 1987: 59n).
} 
perturbations are not drawn into the system, but rather, must gain expression in the terms of the sub-system's internal organizing code. 5 In the case of law, for instance,

... extra-legal norms must be transformed within the legal system before they can assume legal validity; and, in so far as legal norms enter into the calculation of extra-legal systems, they do so because they are deemed relevant according to extra-legal criteria (such as the moral implications, economic costs or electoral repercussions of compliance).

Thus, for events to be made relevant to the legal system they must be cast in terms of the internal organizing code of modern law which is based on 'a self-contained and self modifying system of legally binding decisions' (ibid., 321).6 In these terms, we can begin to understand the bases of law's inherent conservatism in the face of progressive demands. Radical change might cause problems

${ }^{5}$ This approach stands in contrast to traditional systems theoretical approaches with their concentration on input-output flows.

${ }^{6}$ Exogenous perturbations are contended with in one of three ways: they can be ignored because they have not been articulated in the organizing code of the system or are passed off as being more appropriately contended with by another sub-system; they can lead to sui generis internally determined reactions whose principle role is to reestablish system identity and 'maintain the basic organization of the system' (Jessop 1987: 43); or finally, they can be so severe as to lead to systemic disintegration. Thus, when confronted with environmental perturbations an autopoietic system does not necessarily 'adapt optimally or pursue a predetermined function... [but rather] adapts in whatever ways will enable it to maintain its basic structure' (ibid.: $41-42$ ). 
for other social systems which rely on the law to generally provide a positive degree of flexibility ${ }^{7}$ whilst, in any one specific area of law, maintaining a degree of consistency adequate to sustain its legitimacy as the primary mechanism for normative regulation in the modern world.

In terms of the relationship between autopoietic systems, such systems 'can be coupled together structurally without losing their respective identities. This can happen as long as their autopoietic responses serve as reciprocal sources of compensable perturbation'(Jessop 1987: 39).

Social sub-systems are continuously engaged in a process of blind co-evolution with both other sub-systems and the environment generally. No one system necessarily dominates the others as essentialist conceptions would have it, although Luhmann does concede that the most complex subsystem is likely to have the most preponderant effects on other systems and that in the 'modern' world that sub-system is the economy (Jessop 1990: 333 ).8

${ }^{7}$ That is, to be flexible across its many types of law. ${ }^{8}$ For Luhmann, ... the functional sub-system which attains the greatest degree of organized complexity and flexibility through its own internal organization will also tend to dominate the society in which it is located. For the dynamic of this sub-system will have a disproportionately great influence on the performance of other sub-systems. He has also suggested that in modern societies, this subsystem is, in fact, the economy. 
Teubner points out that systemic co-evolution is further guided by the principle of functional equivalence (1987: 227; c.f. Luhmann 1988: 121-122). For Teubner, although some sub-systems may be functionally optimal for the regulation of specific social relations, this does not mean that conjunctural forces will be such as to ensure the emergence of the optimal system as the ultimate regulatory system. For instance, political relations (i.e. social relations of power) are oft-times regulated through legal relations. The central concern for autopoieticists is to ensure that law not be used as a mechanism for substantive political or economic change, and thus over-extend its functional capacities. Such an event would lead to anomic tendencies toward systemic disintegration as, they argue, has been the case with the modern regulatory welfare state. 9 Thus, because it exists in a relation of

Thus, it is consistent with autopoieticism to assert the possibility of asymmetry in the processes of structural coupling such that 'the economy plays a key role in determining how different systems are coupled' (Jessop 1987: 95). At this level we can recognize the validity of Glasbeek and Mandel's concern with the economy's impact on other areas of social life. In these terms, traditional marxist foci on the nature on the economic as a primary motor for developments in other areas of the social retains a strong foundation. What needs to realized - and what Glasbeek and Mandel fail to recognize - is that the economy is only one (albeit very important) such motor.

${ }^{9}$ In particular, such relations have often come to be subject to regulation via instrumental regulatory law (Teubner 1984, 1987). In Weberian terms, the rise of a legally regulated welfare state has led to a shift from formal rationality (or autonomous law) to substantive rationality (Handler 1988: 1042-1043). Much of Teubner's 
functional equivalence with other social systems, law can colonize aspects of social regulation optimally regulated by systems other than law. As I will argue below, functional equivalence thus contemplates the insertion of an element of strategic selection into the question of which social subsystems might actually emerge in a given conjuncture as regulating specific social relations.

It is impossible to do justice to this complex body of work in so short a space. But from the foregoing we can glean a number of insights regarding the growth of law, its seeming resilience in the face of progressive challenges, and its autonomy from other aspects of the social. In sum we can say that autopoieticist analyses stress the contingent evolution of social systems and the emergent properties of self-referentiality which come to constitute a fundamental component of systemic autonomy. However, whilst in this account there is ample attention paid to the structural conditions of social existence there is no accounting for the ways in which individuals might, to paraphrase Marx, confront the circumstances of their existence and actually make their own history (1974: 146).

work concentrates on a critique of the legal element of the regulatory welfare state on the basis of its sub-optimal functional equivalence $(1984,1987,1988)$. Habermas is working on parallel analyses of anomic general tendencies arising out of an overextension of law with his distinction between law as an institution and law as a medium (Habermas 1987; Eder 1988; C.f. Luhmann 1985, 1987, 1988; cf. Reich $1988)$. 
In its almost exclusive emphasis on structure there is little or no mention of agents, collective or individual, in autopoietic analyses. The systems-theoretical approach of Luhmann et al reduces individual and collective interaction, rather, to that 'countless systems of face-to-face interactions' (Luhmann 1988: 123), hardly a useful conceptualization for trying to understand social struggle. In the absence of any conception of agents we are presented with 'the hard form of structural determinism... [in which] subjects orient themselves, in a complex society, to norms, rules and laws in order to overcome crises generated by the overproduction of choices'(Milovanovic 1988: 403). In response to structuralist analyses Mahon suggests that social structures:

... do not determine the course of history and agency can matter a great deal if the strategies adopted by actors are based on an accurate (albeit dynamic) understanding of the possibilities opened up (and foreclosed - at least temporarily) by existing ... structures.... A]ctors can learn from analysing the unanticipated consequences of past actions and thus alter their pattern of strategic conduct.

(Mahon 1991: 137)

Jessop has recently turned his attention to trying to draw out the positive aspects of autopoieticism in an effort to enhance marxist conceptions of the autonomy of socialrelational structures. Jessop, quite correctly in my view, takes autopoieticism to task for its treatment of autopoietic systems as reflexively closed communicative structures. What gets lost is a conception of 
interdiscursivity between social sub-systems, and between sub-systems and actors. He suggests that:

To provide a more satisfying account we also need to explore who communicates with whom about what (and how these particular agents came to be constituted and to have these concerns); and to consider the projects which these agents tried to realize in making their own history, albeit in circumstances which they did not choose and with consequences which they could not foresee, did not always intend and can never fully control. To explore these issues we need to deal with agency as well as with social systems.... One is sometimes led to believe that the only differences which matter in Luhmann's social theory are those which establish the distinction between a system and its environment'.

$(1990: 334-335)$

Law, I will argue, is crucial to these processes in its role as the transpositioning discourse in 'democratic capitalist countries'(Woodiwiss 1985, 1990). This role renders law a critical object of struggle for all social movements, and is a central point of selection in the boundary construction of the universe of political discourse (Jenson 1987a, 1987b, 1989, 1990). What is important to understand is the role law plays in the constitution of different discursive formations; the ways in which agents struggle both within and without law in an effort to achieve specific 'political' effects. As Hunt suggests:

... law constitutes or participates in the constitution of a terrain or field within which social relations are generated, reproduced, disputed and struggled over. The most important implication being that within such a field, which Foucault would designate as a discursive formation, the legal discourses in play both place limits of possibility on social action and impose specific forms of discursive possibility. 
This terrain is not reducible to law, but is, rather, the terrain of social power relations. Law is, however, a crucial component in determining the topography of that terrain in a given conjuncture. Moreover, law can play a vital role not only in the constitution of hegemonic effects manifested at a broad societal level, but is also crucial to the emergence of specific hegemonic configurations at the level of specific knowledges. Law then is vital to the constitution of 'local hegemonies' (Hunt 1990), the development of which are dependent upon the outcome of political struggle. ${ }^{10}$

\section{Law and the Transpositioning of political subjects}

Not all social issues achieve 'political' status; nor do all issues or actors achieve the designation 'political'. Popular discourse and the struggle for political space renders some essentially private, economic, religious, etc, beyond the legitimate purview of the realm of politics. '[B]eliefs about the way politics should be conducted, the boundaries of political discussion, and the kinds of conflicts [perceived popularly as] resolvable through political processes'(Jenson 1987b: 65) combine to constitute the universe of political discourse.

${ }^{10}$ Hunt defines 'local hegemony' as 'the construction of some hegemonic project within some particular area or region of social life'(1990: 313). 
The universe of political discourse sets the boundaries of political action and places limits on 'the range of actors that are accorded the status of legitimate participants, the range of issues considered to be included in the realm of meaningful political debate, the policy alternatives feasible for implementation, and the alliance strategies available for achieving change'(ibid.). Law and legal discourse play a central role in the demarcation of these boundaries. Woodiwiss describes this role as follows:

In the same way that the law intermittently adjudicates as between the rights and duties of individual agents, so it also adjudicates on the relative acceptability or otherwise and, therefore, on the wider social influence of particular discourses as well as on particular sets of political and economic relations. ... [Law] does not simply contribute to the securing of social order by disciplining agents, but also contributes significantly to the definition of the nature of that order by allowing the defining and redefining of the social order's structure and content every time a judge makes a decision [and, it should be added, every time a legislator legislates ].

$(1990: 121)$

But what must be stressed is that the legal order, both its form and content, is not impervious to the unequal structure of social relations, but rather, constitutes a condensate of past struggles. Law not only acts upon the social body, but is acted upon as well.

Any sense of a dynamic political symbiosis between law and society largely evades autopoieticists. For them law may 'colonize' other spheres of normative social regulation, but this is portrayed as a largely passive process whereby 
the legal system naturally usurps (through hit-and-miss contingent processes of functional equivalence) the regulation of hitherto informally regulated normative orders. Clearly there is a recognition that there is a twoway relation here - law codifies norms that are already 'out there' and individuals pattern their expectations on the basis of these codifications - but there is little space here for a suggestion that law itself might codify the objects of struggle, not merely by virtue of the subjects it interpellates, but by those it does not as well.

The concept of functional equivalence, whilst at a descriptive level useful, tends to obscure the fact that the selection of one system over another is not neutral. The concept of strategic functional displacement offers the conceptual space required to accomodate a conception of agency within an autopoietic analytical framework. This concept aims to decentre the most descriptive functionalist aspects of autopoieticism as elaborated by scholars working in the Luhmannian systems-theoretical tradition. Strategic functional displacement provides a necessary addition to the 'theoretical neutrality' of functional equivalence by downplaying the hit-and-miss contingency which dominates the Luhmannian formulation, whilst highlighting the fact that the choice of one system over another is fundamentally political, a result that emerges out of struggle. 
What seems natural or normative to autopoieticists is actually a condensation of the outcomes of past struggles. The capacity of this condensate to partially structure subjects' interpretations of their conditions of existence and to mystify the oppressive nature of some of those conditions renders law a crucial site of struggle.

Woodiwiss has some valuable insights to offer an analysis of law as an interpellative structure which acts as the discourse of transpositioning in such societies. It is worthwhile quoting Woodiwiss at length here:

As an interpellative structure, the law places the subjects it addresses in particular positions relative to one another and itself according to the schema to be found in its component discourses. These positions are constituted by the rights and duties that define them and which therefore determine the relations that can or should exist between them (for example husband/wife, employer/employee and citizen/state). Now of course such positions and such relations are also defined and confined by other discursive and non-discursive positionings apart from those specific to the law. As a consequence, legal discourses possess a varying substantive content according to which sets of non-legal discourses they refer to. The pertinence of these positions being defined in law is that, when the disciplinary balances achieved by these other means breaks down, they may be reinforced, mediated or terminated by invoking the law. More particularly, given the law's intrinsic technology, this reinforcement takes the form of a discursive, and sometimes non-discursive (that is, where some kind of physical constraint or distraint is involved), compulsory transpositioning, so as to effect an exclusion of other mechanisms.

(1990: 116; C.f. 1985) Law is thus one interpellative discourse in society, but is particularly important given its role as the 
transpositioning discourse. Moreover, it has disciplinary effects, effects that obtain 'through the discipline that inheres in successful interpellation - i.e. interpellation achieved against the resistances produced by the other discourses that construct the subject' (Woodiwiss 1985: 71).

But as only one of many interpellative structures, it acts only intermittently, and must compete with other interpellative discourses. That is, law only has direct effects when legal action is taken or when actors' behaviour is circumscribed proactively - i.e. as through constitutional or criminal law (Woodiwiss 1990: 116-119). 'outside of such situations subjects are interpellated and their relationships governed by other discourses' (ibid., 119). It is in this sense that law only partially structures subjects' perceptions of their conditions of existence, as I suggested above.

The successful interpellation and disciplining of subjects is dependent upon whether or not these subjects are able to 'successfully resist this disciplining because of prior or other interpellations originating in and articulated with counter-discourses'(Woodiwiss 1985: 73). ${ }^{11}$ Included in these competing discourses are those of the 'disciplines of the modern episteme' as smart and Foucault

${ }^{11}$ Thus, law clearly does have a pedagogic role in society as Glendon (1987) suggests. However, its nature as an intermittent interpellative structure highlights the fact that that role is in no way necessarily determinative of lived social relations. 
stress. But so, too, are discourses of resistance. Indeed, as the condensation of normative rules, law's broad-scale failure to successfully interpellate subjects can establish an impetus for change in the law.

But law enjoys a relative advantage over competing discourses, insofar as it is the social discourse of consistency and calculability, a fact that arises out of the relative closure of its signifying hiatus (Woodiwiss 1985 , 1990).12 It is this central role in positioning,

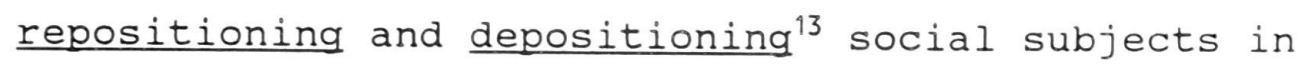
relation to one another, specifying rights, duties and obligations - be they compulsory or potential - that provides us with an understanding of the role of law which improves on the inadequacies present in the models presented

\footnotetext{
${ }^{12}$ Woodiwiss points out that:

... the very possibility of legal transpositioning requires that legal discourse, unlike literature (Derrida, 1977) and dreams (Lacan, 1977), exhibits a relative closure of the signifying hiatus and a consequent [relative] consistency in its use of concepts... [ $\mathrm{T}]$ he law is characterized by an inherent strain towards consistency because of its own systemic requirements as a discourse in a determinate social location, rather than because of any needs of its human subjects.
}

$(1990: 117)$

It is this closure and consistency which gives to law its specific effectivity, rather than merely its integration with the repressive/violent apparatuses of the state (contra Poulantzas 1978).

${ }^{13}$ Repositioning is the process whereby subjects gain positions they had not previously held, thus altering their pre-existing positionings. Depositionings, on the other hand, is the process whereby subjects cease to occupy the positions they previously held, thus altering their preexisting positionings (Woodiwiss 1990: 117). 
in chapters two and three. It is important to understand that, once inscribed in law, formal identities can pave the way for substantive social change.

Returning momentarily to smart's analyses, we can now see how her insight regarding the power of law to qualify some social actors and disqualify others stands as perhaps her most important. This same point is one the autopoietic systems- theorists miss. Social struggles around law consist largely of attempts by collective actors to shift their position(s) relative to other actors. Law thus provides a forum through which subjects can articulate a repositioning or depositioning of social places they occupy within the context of a state-enunciated and enforced discourse (Woodiwiss 1985: 73). Importantly, the autopoietic closure of the legal system coupled with the relative closure of the signifying hiatus renders law an important basis for positional stasis.

In the following, concluding chapter, the discussion draws both upon the foregoing theoretical alternative and the historical analyses of chapter one in an effort to derive some insights about the seeming growth of law, the social role of law generally, and its resistance to change. In so doing, it endeavours to employ autopoieticism and transpositioning as a means to shed some light in those areas that Glasbeek and Mandel and Smart fail. 


\section{Summary}

This chapter set out to discuss some recent theoretical developments that might help us better understand a) the perceived drift toward juridification of social relations; b) the nature of law's seeming resilience in the face of demands for progressive change; c) law's capacity to preclude the participation of some actors and identities within a broader set of state enunciated and enforced discourses. Luhmann's conception of heightened functional differentiation and complexity provided the point of departure. Coupled with his conception of the positivisation of law, we can begin to understand an increase in both the social scope and density of law as a function of heightened social complexity, whilst the autonomy and resilience of law might be understood as a function of its autopoietic closure. Moreover, autopoietic analyses promise some insights into the nature of law's articulation with other social discourses through the process of structural coupling. Ultimately, however, autopoietic analyses, in their Luhmannian form, suffer from an over-emphasis on structure to the almost complete absence of a conception of agency.

In turn, the subsequent section was dedicated to coupling a notion of agency with autopoiesis which might help us better understand the role of law as a terrain of struggle. As such law was described as the discourse of 
transpositioning of subjectivities in advanced capitalist societies, a role critical to the establishment of the boundaries of the universe of political discourse.

Reconceiving of law in this way holds out some promise in terms of offering a potentially more nuanced theoretical account of the place of law in social struggle. The concluding chapter attempts to develop just such an account, through a re-examination of the historical material developed in chapter one. 


\section{Conclusions}

Law and struggle: Putting Law Back in Progressive Politics Chapters two and three focused on two examples of what I have called 'juridification' theses. As such, each of these accounts endeavours to explain aspects of what the authors see as the growing centrality of law in advanced western societies. In each case, the expansion of the scope of law in contemporary western societies is viewed in a pejorative light - law is largely seen as a mechanism for the reproduction of prevailing social relations of domination, and progressive victories at law are treated either as primarily chance events, or worse, as instances of the cooptation of the oppressed through the legal mechanisms so vital to the maintenance and reproduction of their oppression. Neither approach provides an adequate basis for a theoretical understanding of the mechanisms underlying the juridification of social spaces hitherto free from statecentred legal regulation. Moreover, both provide accounts of law that are riddled with an essentialism that paints law as inherently antithetical to progressive struggles.

of course it is important to highlight how limited progressive legal strategies have often been in generating the impetus for substantive social change. It is also important to recognize that law often does tend to favour the status quo, thus reinforcing/ reasserting the legitimacy of prevailing social relations of domination/ subordination. 
It is in these senses that the authors reviewed above do succeed. But whilst law often does display these tendencies, does this mean that law should be avoided as medium for the advancement of social change? I have argued above that there is nothing inherent in law or the legal form that necessarily renders it an instrument of the most powerful social interests." Law's tendency to often favour the status quo is a product, not of any necessary correspondence between it and particular social forces, but rather, of its specific requirements as the discourse of consistency and closure in modern societies. A critical theory of law must endeavour to understand the bases of progressive victories at law, and the structural rigidities that place limitations on the substantive potential of legal struggle. But such a move involves a rejection of the tendency to marginalize past victories at law as mere exceptions, or worse yet, as moments of cooptation.

In an effort to move away from the debilitating sorts of reductionisms present in the work of Glasbeek and Mandel and smart, chapter four moved to a more specific discussion of law and its development, drawing on insights from autopoieticism. The conceptualization of law as an autopoietic social sub-system offers a new and potentially more fruitful way of understanding the expansion of the

'Indeed, if law merely reflected social relations located elsewhere, a study of law would be rendered redundant. 
legal order, one that helps avoid some of the cruder reductionist tendencies in the approaches examined in chapters two and three. Moreover, this approach offers a new way of theorizing not only the role and nature of law, but the relation of the legal sub-system to its environment and its relationship with other social subsystems.

In terms of juridification tendencies generally, we can begin to understand the growth of law as a social-systemic by-product of heightened functional differentiation. Looking back to the onset of the Canadian state's adoption of criminal legislation restricting access to abortion, abortifacients and contraceptives, we can identify the Canadian experience with the early phases of 'autopoietic takeoff' of the modern regulatory state.

The early nineteenth century turn to legal regulation of abortion and other hitherto 'informally' regulated matters of social morality might be said to constitute a genuine expansion of law. But beyond this initial thrust there is little to suggest there has been any genuine expansion in the laws regulating abortion since these early years. Even if the Criminal code revisions of 1969 might be argued to have constituted a genuine increase in the density of law, that increase was arguably negligible given the fact that a therapeutic exception had long existed in common law 
(Habermas 1987: 357 ). ${ }^{2}$ In these terms, it would seem that the criminal code revisions displaced a complex system of common law rules regulating therapeutic exceptions, replacing it with a new system of regulation that had its basis in the criminal code. It is difficult to see how this might be seen as amounting to a substantive increase in the density of law.

The situation in 1988 was notably different. The striking down of $\mathrm{s} .251$ of the criminal Code in Morgentaler [1988] represents an important shift in the type of law regulating abortion. Now the terrain has shifted from the overtly oppressive criminal law to the realm of laws regarding medical and health services provision (more generally, welfare state regulation). At this point it is unclear whether or not we might see movement back to criminal regulation of abortion. Moreover, the shift to a new form of law does not imply a necessary trajectory in the development of abortion services provision. This shift may,

${ }^{2}$ Habermas suggests that in endeavouring to understand juridification processes we should distinguish between 'the expansion of law, that is the regulation of new, hitherto informally regulated social matters, from the increasing density of law, that is the specialized breakdown of global statements of the legally relevant facts [Rechstatbestände] into more detailed statements' (Habermas 1987: 357). BY 'density' Habermas seems to be specifying a conceptual distinction whereby we might be better able to grasp an increase or decrease in the range of social actions regulated by law. Thus an increase in the density of law would imply a movement from 'general' regulation to the regulation of progresively more specific social acts. 
however, constitute the basis for change in the way that struggles around the issue are articulated.

Once again, these insights call into question the implication that the legal regulation of women's fertility somehow represents one manifestation of a broader trend in recent years toward juridification of the social. But, at the same time, this would seem to lend some support to Smart's connection of the growth of law with the rise of medicine as a crucial discipline. This leads us to consider what autopoietic analyses might have to say about the connection between medicine and law.

In the relationship that arose between law and medicine, law both recognized and legitimated the emergence of an organized medical system. The medical community became, through the legal establishment of boundaries as to who could control specific knowledges, the gatekeepers to 'health' knowledge. Clearly, as McLaren and McLaren (1986: passim) show, this did not eliminate the existence of traditional methods of contraception, self-inducement of miscarriage, or even word-of-mouth networks by means of which women could find abortionists. However, the medical community's efforts surely paid off for the ranks of the 'regulars' as obstetrics and gynaecology took over many (if not most) aspects of women's health care which had traditionally been the object of folk remedies and midwifery. 
A 'neutral' reading of developments toward autopoiesis in medicine and law might suggest that the rise of medical control over such issues was a natural by-product of an evolutionary process of functional differentiation - the medical 'system' was better equipped than traditional sources of these knowledges to organize the trend toward increasing complexity and specialization in health care. But the historical review in chapter one suggests that this was not at all the case. Rather, abortion and contraception were issues that were struggled over, and the forces which ultimately achieved local hegemony in these matters did not view these as representing genuine needs of women. This nascent medical 'community' successfully adopted abortion (and other reproductive issues) as a cause célèbre - one which constituted a primary base upon which it endeavoured to establish the scientificity of its own claims for the regulation of the health industries generally. It was also an effort which saw the genesis of an autopoietic medical system, the take-off of which was facilitated through the institutionalized exclusion of women in law from public decision-making on issues related to their reproductive capacities. Moreover, these developments led to the exclusion of women's knowledge and experience which was often either greater than that of the medical regulars, or which could put women in touch with individuals (i.e. professional abortionists) whose expertise was. 
It is crucial to recognize (as chapter one attempted to show) that this was not an innocuous development arising from a natural evolution of medical discourses. It was, rather, very much the result of a strategic coup in the medical 'profession's' attempts to organize and regulate both its membership and the scope of their professional activities. Thus, medical regulars won a strategic battle for the regulation of health matters for which they did not have a natural monopoly but, rather, a functional equivalence with the knowledges of women regarding their reproductive capacities. Indeed, Backhouse's (1983: 75, 87) contention that in the early years doctors' methods were often less reliable and more dangerous than those that women would pass on by word of mouth or than those employed by professional abortionists, would seem to call into question the very notion of functional 'equivalence'. Instead, the displacement of professional abortionists and traditional reproductive knowledges by the medical regulars can be more adequately conceived of as an example of strategic functional displacement. Such a displacement, in Woodiwiss' terms, represented a repositioning of medical regulars. Thus, applying the concept of autopoiesis to an historical analysis of legal regulation of reproductive issues in Canada we can see how the legal system, in its evolution as an autopoietic system structurally coupled with the medical system, was able to condense a specific 
constellation of social relations in its approach to normative regulation. But, this constellation can hardy be said to have been politically neutral; rather, it permitted the perpetuated marginalization of some identities as valid interlocutors in issues surrounding reproduction and fertility, whilst legitimating others. The origins of these exclusions are to be found in the discourses of traditional morality which had hitherto dominated these issues, their insertion into the 'scientific' discourses of medicine, and their capacity to draw on and perpetuate popular discourses of eugenics. This process was vital to the formative processes of an emergent autopoietic medical system.

The autopoietic closure of the medical and legal systems was crucial to the constitution of a stable structural coupling between the medical and legal communities and formed the foundation of a local hegemony vis-à-vis issues of reproduction and fertility - a local hegemony that defined which identities would have a legitimate voice in public debate surrounding these issues. ${ }^{3}$ The viability of competing interpretations would now be largely shaped by whether or not the agents

${ }^{3}$ It is precisely these sorts of condensations that underlay the 'dark side' of the new 'disciplinary power' that is of such central concern to smart and Foucault, although a methodological dedication to analyses of power 'in those points where it becomes capillary' (Foucault 1980: 96) at the expense of considerations of inter-systemic strategic alliances tends to obscure such insights in their analyses. 
contesting the impacts of the relevant laws actually had standing as identities recognized in law - i.e. was there space in which such agents could assert their claims within the terms of law's organizing code(s). For years, women would not constitute one of these identities.

This local hegemony would come to be increasingly challenged in the post-war era by a number of environmental perturbations which not only challenged that hegemony directly from the outside, but also revealed contradictions within and between each of these autopoietic systems. As the historical review in chapter one suggested, contradictions at law, rooted in failed legal regulation of women's reproductive careers, were accompanied by growing contradictions within the medical community arising out of advances in reproductive and related technologies and treatment techniques. Tensions arose as the defense of necessity to save the life of 'the mother' became increasingly obsolete. These events were coupled with a new discourse of familialism in the post-war years, one which stressed family planning and population control. More recently we have seen the attempted technological-discursive construction of the foetus as a person through the 'foetal images' campaigns and the activities of right-to-life groups. ${ }^{4}$

${ }^{4}$ The foetal images campaigns cannot be reduced to the activities of right-to-life groups. While these images have been an important part of the pro-life campaigns, many of 
But there were two other crucial sources of the push for reform. Both of these can be related to the notion of failed (legal) interpellations. The first of these was the failure of the law to successfully (re)construct women's experiences. As Rosalind Petchesky has pointed out, '[t]he remarkable thing is not that those in power have attempted to control population by controlling the fertility of women but that they have been so unsuccessful. They continually run up against the everyday practices of ordinary women, in having or not having children according to their own sense of their needs' (Petchesky 1990: 26). In their everyday practices, women have continually challenged the traditional doctor-patient relationship, deciding for themselves what needs to be done - essentially self-diagnosing - and in so doing, challenging the local hegemony of the medical and legal systems over reproductive issues (Gavigan 1986: 281).

The other factor was Morgentaler himself. In refusing to alter his practice, even when the repressive arm of the law had been brought to bear against him, Morgentaler confronted the law head-on. The public nature of his defiance caused an open contradiction, well captured in the

the visual images of the foetus have been presented innocuously, using the foetus as a symbol for a multiplicity of values not immediately reducible to the abortion controversy. What is important to point out is that these images are by no means innocuous; rather, in their presentation of the foetus as somehow separate from the mother they constitute a powerful ideological tool that has been very effectively adopted by the pro-life forces. 
Globe and Mail's suggestion that a 'law so widely disobeyed "brings all law into contempt"' (as cited in campbell \& pal 1989: 172). The discourse of legal closure and consistency was publicly flaunted as one which increasingly no longer accorded with the way many people saw the world (or at least those aspects of it related to abortion). Such contempt and a concomitant delegitimation of law's power shows just how permeable law is to social contradiction and struggle.

All of these forces have converged in recent years to provide the basis for a burgeoning popular discussion surrounding the issue of abortion in Canada, while simultaneously posing fundamental challenges to the stable structural coupling that had hitherto existed between the legal and medical systems around issues of reproduction. But the confluence of such a broad array of forces and events would seem to call into question the Luhmannian assumption that radical intrusion into the structure of the autopoietic system should likely portend its disintegration or functional defectivity. In the work of Luhmann et al, autopoietic closure and the threat of systemic disintegration are used to challenge the incursion of legal regulation into areas of social life that are better left to more purely political practice (i.e. contra the regulatory welfare state). But a consideration of the many factors that have attended the evolution of the abortion issue over the years and have assailed the medical and legal 'systems', 
one is left wondering just how much environmental perturbation it would take to cause systemic disintegration. It would seem, rather, that more attention ought be paid to functional adaptation in the face of environmental perturbation.

With Morgentaler, potential new space has opened for the re/depositioning of subjects in a new compromise, and for a rearticulation of the politics of reproduction in Canada. However, the constituents of the compromise - the identities and issues which will take the fore - are as yet unsettled. Whether or not women will be able to gain a greater degree of self-determination over their reproductive capacities, or whether the gains made to date will be reversed, remains to be determined by the struggles currently under way in Canadian law and politics.

The foregoing offers a fresh perspective from which to examine the nature of the symbiosis smart claims exists between the 'disciplines of the modern episteme' and law. We can see now that the emergence of dominant discourses of the disciplines is not pre-determined, but rather presupposes the active intervention of collective and/or individual agents struggling over the identity boundaries of the universe of political discourse.

The approach outlined here also calls into question just how 'blind' the co-evolution of autopoietic social systems really is (contra Luhmann). Thus, we can see here 
the limitations of Luhmann's apparent assumption of the relative neutrality of autopoietic systems and the notion of their auto-genesis out of the evolution of social complexity and functional differentiation. What is presented by Luhmann as a process of chance evolutionary functional differentiation is actually shot-through with political struggle. The stability of a structural coupling with the legal order is largely dependent upon that coupling's concurrence with the way individuals experience their lives. The degree to which competing discourses better 'fit' the ways in which subjects conduct and experience their lived relations will determine the stability of a particular local hegemony. A poor fit can lead to systemic crisis, one of the outcomes of which may be mediated by the transpositioning role of law in such a way that new actors and identities are able to gain legitimate space in the universe of political discourse.

In the Canadian case, the different forms of law litigation and legislation - have taken on a new dimension with the adoption of the charter. In relation to the abortion issue, the charter has opened up the possibility for feminists to adopt pro-active litigation strategies in an effort to enhance the position of women in Canadian society. The partial victory achieved by Morgentaler was in many respects a profound one. Perhaps most notably, it accomplished in the courts what, by all indicators, would 
have likely taken years in the legislatures: it provided the potential basis for a repositioning of identities in the universe of political discourse such that women might now genuinely go on the offensive in efforts to advance their right to control their own fertility.

The charter opened up space for both the repositioning and depositioning of subjects at law, in turn opening the way for possible insertion of new political and legal

identities on the political scene. But it is only through a combination of broader social struggle and organization, and struggle within the state and law, that women have ultimately gained (however tenuously) the space to articulate such an identity.

Morgentaler stands as a crucial point in the articulation of identities whose interests could be advanced within the context of a state enunciated and enforced discourse. Prior to that case, 'women', as a collective actor, had no formal status in law insofar as the issue of abortion was concerned: they were largely reduced to their reproductive capacities as mothers or potential mothers, or were, conversely represented as degendered neutral agents whose interests in the issue were overshadowed by the scientism and professionalism of the medical community and the reflexive nature of the legal system.

The historical compromise condensed in law prior to Morgentaler was rendered relatively stable by both the 
structural coupling between the medical and legal communities and the autopoietic closure of the legal system. Reform was thus unlikely to come from any radical logic the court might have derived on its own. Until such time as the legislatures were willing to move substantively on the issue, a stable structural coupling and autopoietic closure precluded any effective transcendence of the existing prohibitive statutes. It was the advent of the charter and, of course, the politics that ultimately shaped its contents - that paved the way for the breach that occurred in Morgentaler.

That it took a doctor's challenge to the charter to actually challenge the local hegemony of the law/medicine coupling might be seen as evidence as to just how impermeable that coupling was. Whilst numerous contradictions - social, political and technological flourished around the issue, it took a politicalinstitutional restructuring of the magnitude of that which accompanied the advent of the charter to effect a breach adequate for a realignment of the parameters of the universe of political discourse. In this sense the need to pursue a litigious strategy was perhaps the only potentially viable political action. Such a strategy may again be necessitated should new restrictive legislation be introduced. Nonetheless, future progressive legal strategies are likely 
to achieve success only if they adopt a critical and cautious approach to employing charter mechanisms. 


\section{Cases Cited}

Akron V. Akron Centre for Reproductive Health, Inc., 462 U.S. 416 (1983).

Attorney General of Canada V. Lavell [1974] S.C.R. 1349.

Borowski V. Canada (Attorney General) (1987), 33 C.C.C. (3d) 402 (Sask. C.A.); affirmed on other grounds [1989] 1 S.C.R. 342 .

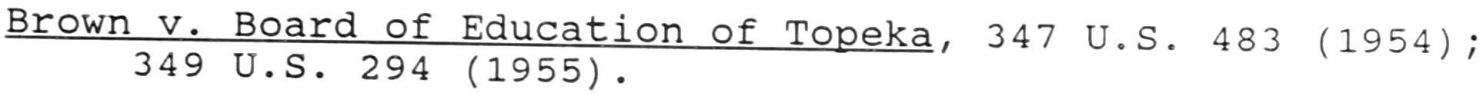

Harris V. McRae 448 U.S. 297 (1980).

Murphy V. Dodd (1990), 63 D.L.R. (4th) 515 (Ont. H. Ct.).

The Queen V. Clarence 2 Q.B. 23 (1889).

$\underline{\text { R V. Morgentaler }}(1988), 1$ S.C.R. 30.

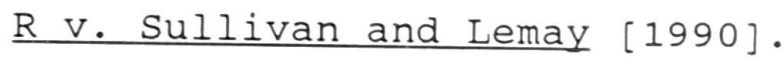

Roe V. Wade 410 U.S. 113 (1973).

Tremblay V. Daigle [1989] 2 S.C.R. 530 (S.C.C.). 


\section{References}

Backhouse, Constance (1983) 'Involuntary Motherhood: Abortion, Birth Control and the Law in Nineteenth Century Canada' in 3 Windsor Yearbook of Access to Justice, 61-130.

Barrett, Michelle (1988) Women's oppression Today: The Marxist/Feminist Encounter. London: Verso.

Bartholomew, Amy and Hunt, Alan (1990) 'What's Wrong With Rights' in 9:1 Journal of Law and Inequality, 1-58.

Campbell, Robert and Pal, Les (1989) 'Courts, Politics, and Morality: Canada's Abortion Saga' in The Real World of Canadian Politics: Cases in process and Policy. Peterborough: Broadview.

Caldwell, Lesley (1986) 'Feminism and abortion politics in Italy' in Lovenduski, Joni and Outshoorn, Joyce (eds.) The New Politics of Abortion. London: Sage.

Cheffins, Ronald and Johnson, Patricia (1986) The Revised Canadian constitution: Politics as Law. Toronto: McGraw-Hill Ryerson.

Collins, Anne (1985) The Big Evasion: Abortion, The Issue that Won't Go Away. Toronto: Lester \& Orpen Dennys Ltd.

Collins, Hugh (1987) 'Niklas Luhmann, A sociological theory of law' Book Review, 10 Contemporary Crises, 347-350.

Cotterell, Roger (1984) The Sociology of Law: An Introduction. London: Butterworths.

Eder, Klaus (1988) 'Critique of Habermas's Contribution to the Sociology of Law' in 22:5 Law \& Society Review, 931-944.

Foucault, Michel (1980) Power/Knowledge, Colin Gordon (ed.). New York: Pantheon.

Fudge, Judy (1987) 'The Public/Private Distinction: The Possibilities of and the Limits to the use of charter Litigation to Further Feminist Struggles' 25:3 osgoode Hall Law Journal, 485-554. - (1989) 'The Effect of Entrenching a Bill of Rights upon Political Discourse: Feminist Demands and Sexual Violence in Canada' 17 International Journal of the Sociology of Law, 445-463. 
Gavigan, Shelley (1986) 'On "Bringing on the Menses": The Criminal Liability of Women and the Therapeutic Exception in Canadian Abortion Law' 1 Canadian Journal of Women and the Law, 279-312.

- (1987) 'Women and Abortion in Canada: What's law got to do with it?' in Luxton, Meg and Maroney, Heather Jon (eds.) Feminism and Political Economy: Women's Work, Women's Struggle. Toronto: Methuen.

- (1990) Morgentaler and Beyond: Abortion, Reproduction and the courts. (draft)

Ginsberg, Fay D. (1989) Contested Lives: The Abortion Debate In an American Community. Berkely: University of California Press.

Glasbeek, Harry J. and Mandel, Michael (1984) 'The Legalization of Politics in Advanced Capitalism: The Canadian Charter of Rights and Freedoms' 2 Socialist Studies, 84-124.

Glendon, Mary Ann (1987) Abortion and Divorce in Western Law: American Failures, European Challenges. Cambridge: Harvard University Press.

Gramsci, Antonio (1971) Selections from the Prison Notebooks. London: Lawrence \& Wishart.

Gotell, Lise (1990) The Canadian Women's Movement, Equality Rights and the Charter. Ottawa: Canadian Research Institute for the Advancement of Women.

Habermas, Jürgen (1987) The Theory of Communicative Action, Volume Two: Lifeworld and System. Boston: Beacon Press. - (1976) 'Problems of Legitimation in Late capitalism' in Connerton, Paul (ed.) Critical Sociology: Selected Readings. Harmondsworth: Penguin.

Handler, Joel (1988) 'Dependent People, the state, and the Modern/Postmodern Search for the Dialogic Community' 35 U.C.L.A. Law Review, 999-1113.

Hunt, Alan (1985) 'The Ideology of Law: Advances and Problems in Recent Applications of the concept of Ideology to the Analysis of Law' 19 Law and Society Review, 101-126.

- (1986) 'A Sociological Theory of Law: By Niklas Luhman' Book Review, 26 British Journal of Criminology, $192-194$. 
(1991) 'Law's Empire or Legal Imperialism' in Hunt,

A. (ed.) Reading Dworkin Critically. New York: Berg. (1990) 'Rights and Social Movements: Counter-

Hegemonic Strategies' 17 Journal of Law and Society, 309-320.

- (1991) Why Did Foucault get Law so Wrong? Reflections on Law, Power and Sovereignty. Departmental Working Paper 91:4, Department of Sociology and Anthropology, Carleton University.

Jenson, Jane (1987a) A False Victory: Women, the state and Abortion (draft).
(1987b) 'Changing

Political Rights and Reproductive Policies in France'

in Katzenstein, Mary Fainstod and Mueller, Carol

Mcclurg The Women's movements of the United States and

Western Europe: Consciousness, Political opportunity,

and Public Policy. Philadelphia: Temple University Press.

- (1989) 'Paradigms and Political Discourse: Protective Legislation in France and the United States Before

1914' 22:2 The Canadian Journal of Political Science, $235-258$.

- (1990) Getting to Morgentaler: From one

Representation to Another. (draft).

Jessop, Bob (1980) 'On Recent Marxist Theories of Law, the State, and Juridico-Political Ideology' 8 International Journal of the Sociology of Law, 339-368.

- (1987) 'The Economy, the state, and the Law: Theories of Relative Autonomy and Autopoietic Closure, EUI Working Papers, 87/263. Florence: European University Institute.

- (1990) State Theory: Putting the capitalist state in Its Place. Cambridge: Polity Press.

Kaminer, Wendy (1990) A Fearful Freedom: Women's Flight from Equality. Reading: Addison-Wesley Publishing Company, Inc.

Kingdom, Elizabeth (1985) 'Legal Recognition of a woman's right to choose', in Brophy, Julia and Smart, Carol (eds.) Women-In-Law: Explorations in law, family and sexuality. London: Routledge \& Kegan Paul.

Lipietz, Alain (1987) Mirages and Miracles: The Crisis of Global Fordism. London: Verso.

Lovenduski, Joni and Outshoorn, Joyce (eds.) (1986) The New Politics of Abortion. London: Sage. 
Luhmann, Niklas (1985) A Sociological Theory of Law. Boston: Routledge \& Kegan Paul.

- (1988) 'The Self-reproduction of Law and its Limits' in Teubner (ed.) (1988) Dilemmas of Law in the Welfare State. New York: Walter de Gruyter.

(1988) 'The Unity of the Legal System' in Teubner, G. (1988) (ed.) Autopoietic Law: A New Approach to Law and Society. New York: Walter De Gruyter.

- (1988) 'Closure and Openness: On Reality in the World of Law. in Teubner, G. (1988) (ed.) Autopoietic Law: A New Approach to Law and Society. New York: Walter De Gruyter.

Luker, Kristin (1984) Abortion and the Politics of Motherhood. Berkeley: University of California Press.

Mackinnon, Catharine A. (1989) Toward a Feminist Theory of the State. Cambridge: Harvard University Press.

McIntosh, Mary (1978) 'The state and the Oppression of Women' in Kuhn, Annette, and Wolpe, AnnMarie (eds.) Feminism and Materialism. London: Routledge and Kegan Paul.

Mahon, Rianne (1991) 'From "Bringing" to "Putting": The state in late twentieth-century social theory' in 16:2 Canadian Journal of Sociology, 119-144.

Mandel, Michael (1985) 'The Rule of Law and the Legalization of Politics in Canada', reprinted in Caputo et al. (eds.) (1989) Law and Society: A Critical Perspective. Toronto: Harcourt Brace Jovanovich Canada Inc.

- (1989) The Charter of Rights and Freedoms and the Legalization of Politics in Canada. Toronto: Wall \& Thompson.

Marx, Karl (1852) The Eighteenth Brumaire of Louis Bonaparte in David Fernbach (ed.) (1974) Surveys From Exile: Political Writings Volume III. New York: Vintage Books. (1867) Capital: Volume I. New York: Vintage Books $(1976)$.

McLaren, Angus and McLaren, Arlene Tigar (1986) The Bedroom and the state: The changing Practices and Politics of contraception and Abortion in Canada, 1880-1980. Toronto: McClelland \& Stewart Inc.

Myles, J. (1988) 'Decline or Impasse? The current state of the Welfare State' 26 studies in Political Economy, 73107 . 
Nelken, David (1988) 'Changing Paradigms in the Sociology of Law' in Teubner, G. (1988) (ed.) Autopoietic Law: A New Approach to Law and Society. New York: Walter De Gruyter.

O'Brien, Mary (1989) Reproducing the World: Essays in Feminist Theory. Boulder: Westview Press.

Offe, Claus (1975) The Theory of the Capitalist state and the Problem of Policy Formation,' in L.N. Lindberg et al. (eds.), stress and Contradiction in Modern Capitalism. Lexington: Lexington Books.

Panitch and Swartz (1988) The Assault on Trade Union Freedoms. Toronto: Garamond Press.

Petchesky, Rosalind (1990) Abortion and Woman's Choice: The State, Sexuality, \& Reproductive Freedom. Boston: Northeastern University Press.

Poulantzas, Nicos (1968) 'The Problem of the Capitalist State' reprinted in Blackburn, Robin (ed.)(1972) Ideology in social sciences: Readings in Critical Social Theory. London: Fontana.

(1978) State, Power, Socialism. London: New Left Books.

Purvis, Trevor (1991) Feminism, Political strategy and Social Struggle: Abortion and Law in the Canadian Context. Departmental Working Paper 91:7, Department of Sociology and Anthropology, Carleton. University.

Reich, Norbert (1988) Reflexive Law and Reflexive Legal Theory: Reflections on Postmodernism in Legal Theory (Diskussions-Papier). Bremen: Zentrum für europäische Rechtspolitik an der Universität Bremen.

Rothman, Barbara Katz (1989) Recreating Motherhood: Ideology and Technology in a Patriarchal Society. New York: W.W. Norton.

Shapiro, Thomas (1985) Population Control Politics: Women, Sterilization and Reproductive Choice. Philadelphia: Temple University Press.

Simon, Roger (1982) Gramsci's Political Thought: An Introduction. London: Lawrence and Wishart. 
Smart, Carol (1985) 'Locating law: a discussion of the place of law in feminist politics', in Brophy, Julia and Smart, Carol (eds.) Women-In-Law: Explorations in Law, Family and Sexuality. London: Routledge \& Kegan Paul.

- (1989) Feminism and the Power of Law. London: Routledge.

Teubner, Gunther (1984) 'After Legal Instrumentalism?

Strategic Models of Post-regulatory Law' 12

International Journal of the Sociology of Law, 375-400. (1988) (ed.) Autopoietic Law: A New Approach to Law and Society. New York: Walter De Gruyter.

(1988) (ed.) Dilemmas of Law in the Welfare state. New York: Walter De Gruyter.

Trudeau, Pierre (1968) Federalism and the French Canadians. Toronto: Macmillan.

Turner, Jonathan (1986) The structure of Sociological Theory (Fourth Edition). Chicago: The Dorsey Press.

Woodiwiss, Tony (1978) 'Critical Theory and the Capitalist State' in 7:2 Economy and Society, 175-191.

- (1985) 'A Theoretical Prologue to a Socialist Historiography of Labour Law: Law, Discourse and Transpositioning' 13 International Journal of the Sociology of Law, 61-78.

- (1990) Social Theory After Post-Modernism: Rething production, Law and Class. London: Pluto Press. 